
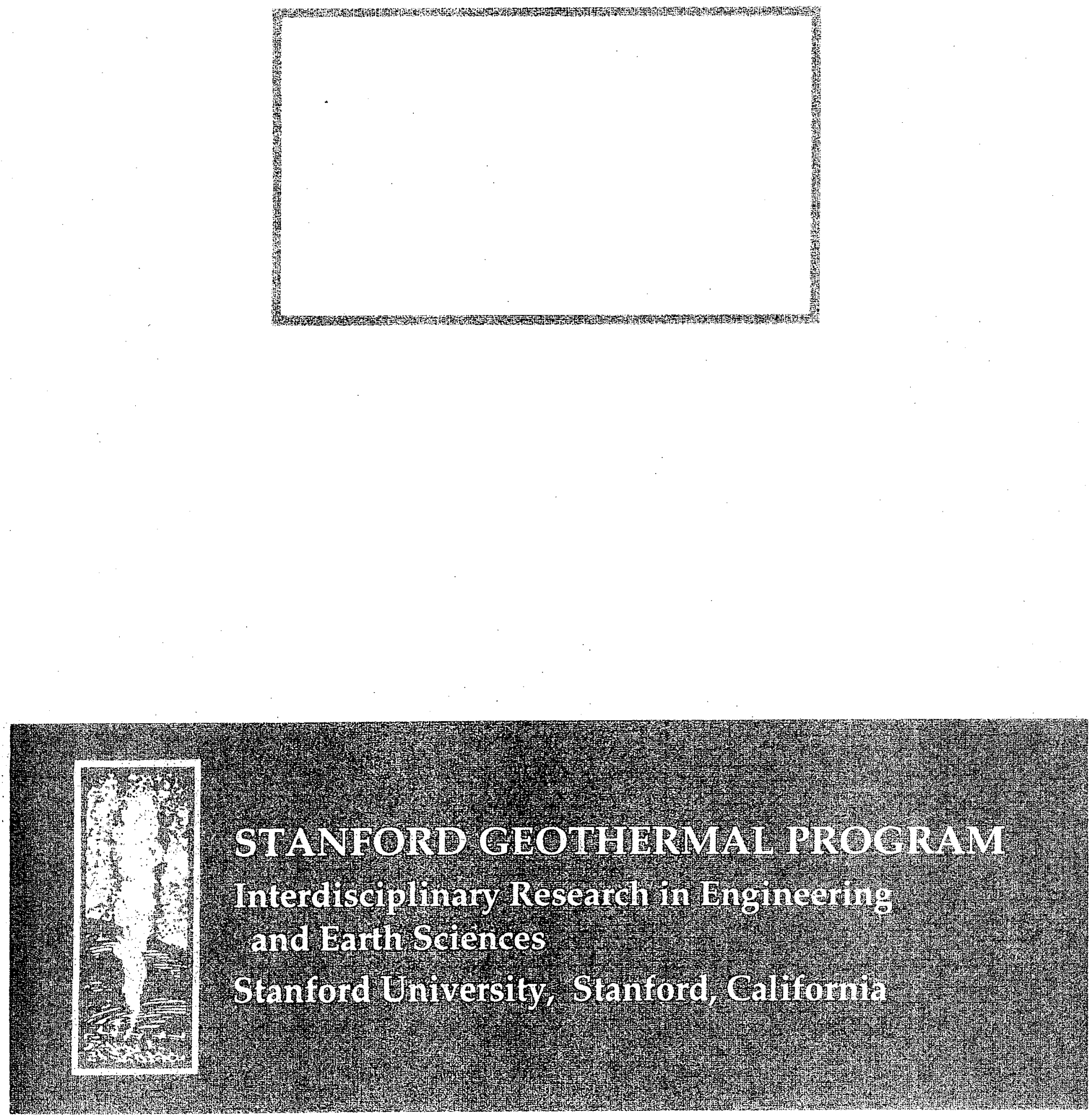


\section{DISCLAIMER}

This report was prepared as an account of work sponsored by an agency of the United States Government. Neither the United States Government nor any agency Thereof, nor any of their employees, makes any warranty, express or implied, or assumes any legal liability or responsibility for the accuracy, completeness, or usefulness of any information, apparatus, product, or process disclosed, or represents that its use would not infringe privately owned rights. Reference herein to any specific commercial product, process, or service by trade name, trademark, manufacturer, or otherwise does not necessarily constitute or imply its endorsement, recommendation, or favoring by the United States Government or any agency thereof. The views and opinions of authors expressed herein do not necessarily state or reflect those of the United States Government or any agency thereof. 


\section{DISCLAIMER}

Portions of this document may be illegible in electronic image products. Images are produced from the best available original document. 
SGP-TR-166

\title{
Boiling Radial Flow in Fractures of Varying Wall Porosity
}

\author{
Robb Allan Barnitt
}

June 2000

Financial support was provided through the

Stanford Geothermal Program under

Department of Energy Grant No. DE-FG07-95ID13370

and No. DE-FG07-99ID13763,

and by the Department of Petroleum Engineering,

Stanford University 


\title{
BOILING RADIAL FLOW IN FRACTURES OF VARYING WALL POROSITY
}

\author{
A REPORT SUBMITTED TO THE DEPARTMENT OF \\ PETROLEUM ENGINEERING \\ OF STANFORD UNIVERSITY
}

IN PARTIAL FULFILLMENT OF THE REQUIREMENTS FOR THE

DEGREE OF MASTER OF SCIENCE

\author{
By \\ Robb Allan Barnitt
}

June 2000 



\section{Abstract}

The focus of this report is the coupling of conductive heat transfer and boiling convective heat transfer, with boiling flow in a rock fracture. A series of experiments observed differences in boiling regimes and behavior, and attempted to quantify a boiling convection coefficient. The experimental study involved boiling radial flow in a simulated fracture, bounded by a variety of materials. Nonporous and impermeable aluminum, highly porous and permeable Berea sandstone, and minimally porous and permeable graywacke from The Geysers geothermal field. On nonporous surfaces, the heat flux was not strongly coupled to injection rate into the fracture. However, for porous surfaces, heat flux, and associated values of excess temperature and a boiling convection coefficient exhibited variation with injection rate. Nucleation was shown to occur not upon the visible surface of porous materials, but a distance below the surface, within the matrix. The depth of boiling was a function of injection rate, thermal power supplied to the fracture, and the porosity and permeability of the rock. Although matrix boiling beyond fracture wall may apply only to a finite radius around the point of injection, higher values of heat flux and a boiling convection coefficient may be realized with boiling in a porous, rather than nonporous surface bounded fracture. 



\section{Acknowledgments}

This research was conducted with financial support through the Stanford Geothermal Program under the US Department of Energy Grant No. DE-FG07-95ID13370. I appreciate the help and guidance of Dr. Roland Horne, as well as the support and advice of Bob Duteau, Dr. Kewen Li, Huda Nassori, and Will Whitted. 



\section{Contents}

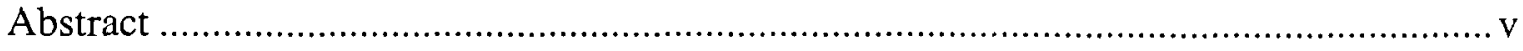

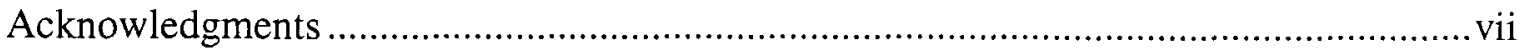

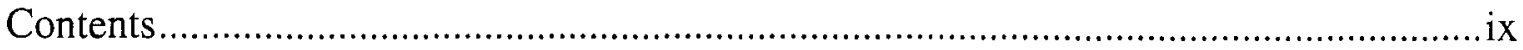

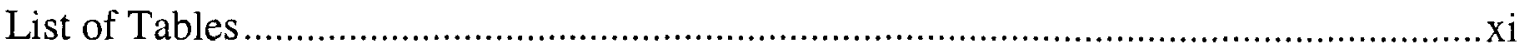

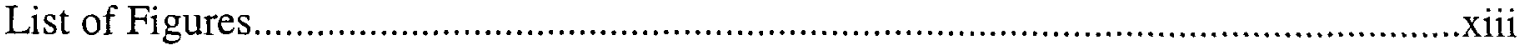

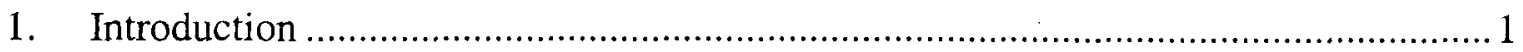

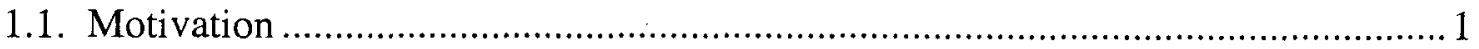

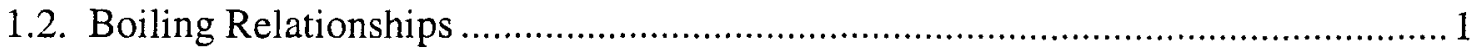

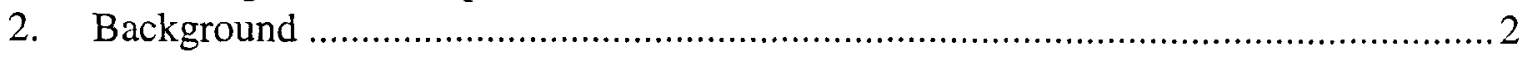

2.1. A Physical Description of Boiling ............................................................ 2

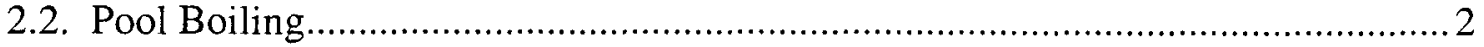

2.3. Effect of Asperities Upon Nucleation .......................................................... 3

2.4. Boiling Curves.............................................................................................. 3

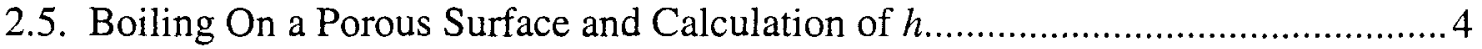

3. Boiling On a Confined Nonporous Surface ..................................................... 6

3.1. Boiling In a Fracture Bounded By Aluminum .............................................. 6

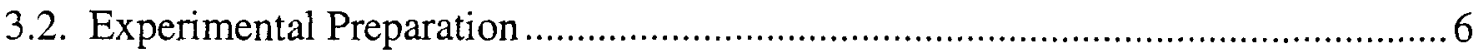

3.3. Experimental Procedure and Conditions ..................................................... 9

3.4. Experimental Observations and Results ......................................................... 10

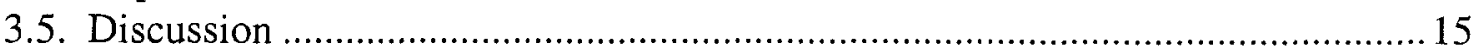

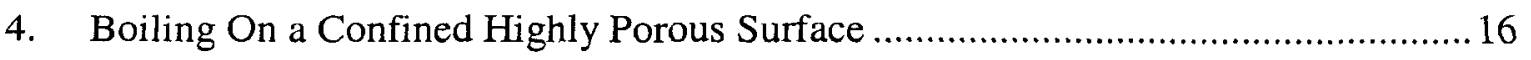

4.1. Boiling In a Fracture Bounded by Berea Sandstone.......................................... 16

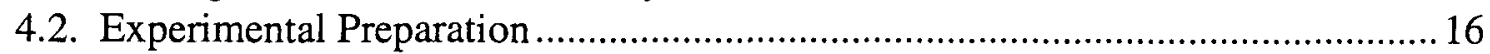

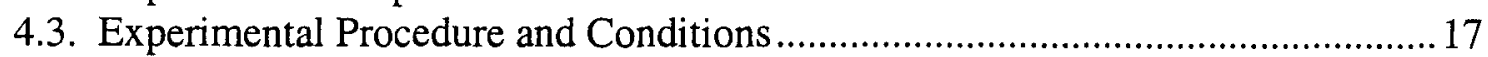

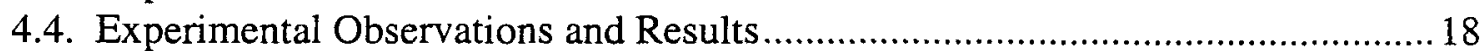

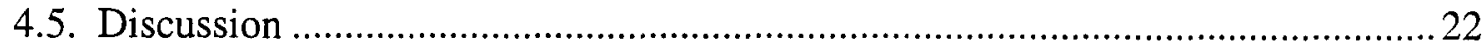

5. Boiling On a Confined Low Porosity Surface ..................................................... 23

5.1. Boiling In a Fracture Bounded By Graywacke ............................................... 23

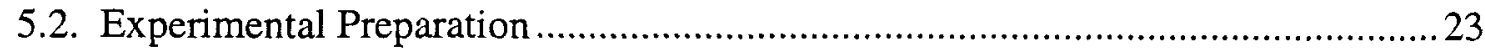

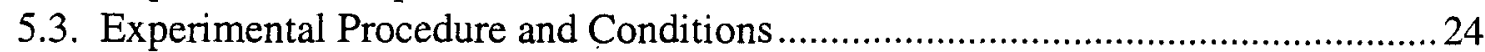

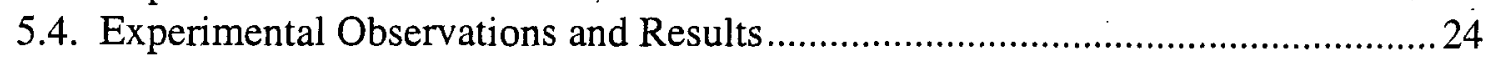

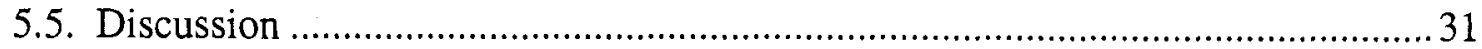

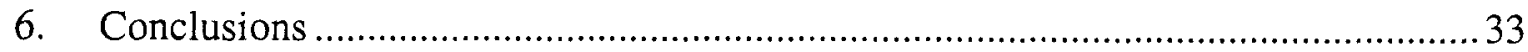


6.1. Data Comparison Over Range of Materials ............................................... 33

6.2. Depth of Boiling In Porous Materials ....................................................... 35

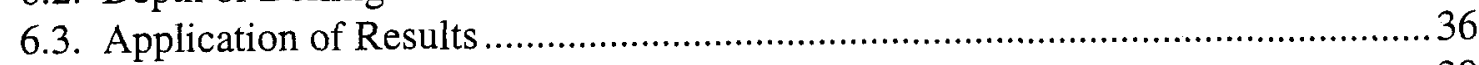

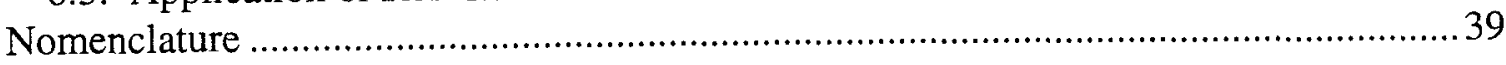

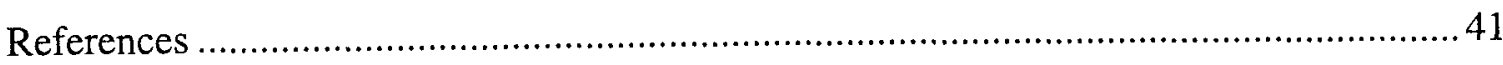




\section{List of Tables}

Table 3-1: Results and Observations - Aluminum Experiment ................................... 12

Table 4-1: Results and Observations - Sandstone Experiment .................................. 19

Table 5-1: Results and Observations - Graywacke Experiment .....................................28 



\section{List of Figures}

Figure 2-1: Boiling Curve Comparison (Kovalev 1987)............................................... 4

Figure 3-1: Heat flux-Temperature gradient measurement experimental apparatus

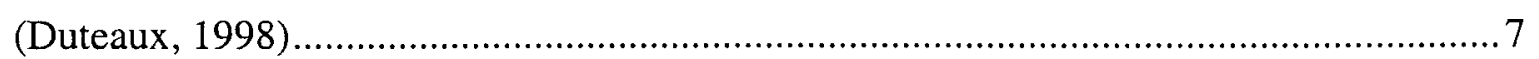

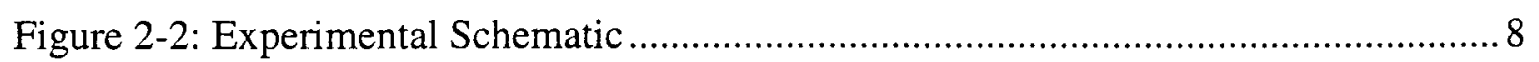

Figure 3-3: Orientation of drilled thermocouple holes in aluminum disk..........................

Figure 3-4: Temperature gradient for varying powers and injection rates - Aluminum

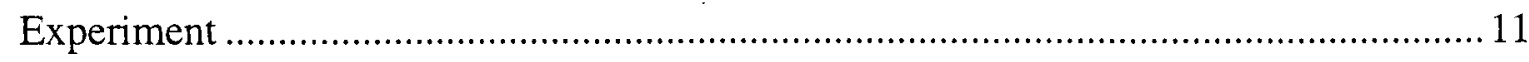

Figure 3-5: Heat flux variance with power and flow rate............................................. 13

Figure 3-6: Excess temperature variance with power and flow rate .................................. 14

Figure 3-7: Boiling convection coefficient variance with power and flow rate ................. 15

Figure 4-1: Dimensions and thermocouple orientation in sandstone disk ........................ 17

Figure 4-2: Temperature Gradients for Three Flow Rates - Sandstone Experiment .......... 18

Figure 4-3: Heat flux variance with injection rate - Sandstone Experiment ......................20

Figure 4-4: Excess temperature variance with injection rate - Sandstone Experiment .....21

Figure 4-5: Boiling convection coefficient variance with injection rate - Sandstone

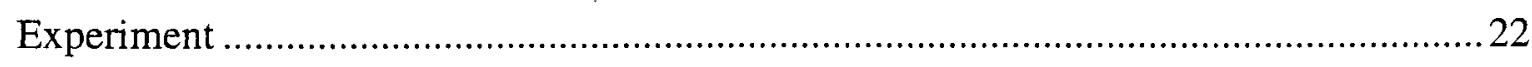

Figure 5-1: Temperature gradients for three flow rates at 300W - Graywacke Experiment

Figure 5-2: Temperature gradients for three flow rates at 350W - Graywacke Experiment

Figure 5-3: Temperature gradients for three flow rates at $400 \mathrm{~W}$ - Graywacke Experiment

Figure 5-4: Heat flux variance with injection rate - Graywacke Experiment....................22

Figure 5-5: Excess temperature variance with injection rate - Graywacke Experiment ...30

Figure 5-6: Boiling convection coefficient variance with injection rate - Graywacke

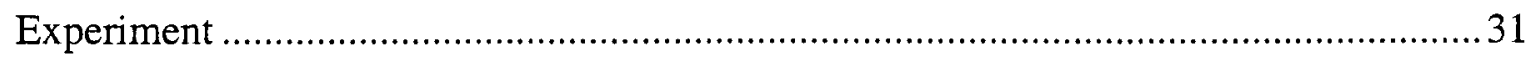


Figure 6-1: Heat flux comparison

Figure 6-2: Excess temperature comparison 34

Figure 6-3: Boiling convection coefficient comparison..... 35

Figure 6-4: Boiling depth variation with injection rate and material 36 


\section{Introduction}

\subsection{Motivation}

Injection of fluid into a vapor-dominated geothermal reservoir, although practiced for some time, is far from completely understood. Of primary importance when injecting fluid into the reservoir is accurate prediction of the point at which liquid flashes to steam. Accurately modeling the transfer of thermal energy to injected fluid is very difficult due to dramatically different time and length scales associated with each. Liquid transport in fractures has been observed to be on the order of tens or hundreds of meters in a few hours (Grant 1982, Horne 1982). However, heat flow in rock associated with vapor dominated systems requires on the order of 30 years to diffuse approximately 30 meters (Pruess 1990). This fact is due to the low matrix permeability, and relatively low thermal conductivity of geothermal rocks. It is therefore necessary to understand the mechanics of the boiling phenomena to predict the length scale required for liquid to flash to vapor in a fractured rock system.

\subsection{Boiling Relationships}

The vast majority of research to quantify heat flux associated with boiling pertains to unconfined pool boiling on a nonporous surface. Established analytical relationships exist for these conditions, but their utility for improved understanding of boiling with injection into a fracture is debatable. This research examined the differences between boiling on an unconfined, nonporous surface, and boiling on a confined, porous surface. The study examined the problem of incompatible length scales inherent in the characterization of fluid flow in high permeability fractures in a matrix of low thermal conductivity. 


\section{Background}

\subsection{A Physical Description of Boiling}

When evaporation occurs at a solid-liquid interface, it is identified as boiling. Boiling begins when the temperature of the surface $\left(T_{\text {surf }}\right)$ exceeds the saturation temperature $\left(T_{\text {sat }}\right)$ corresponding to the liquid pressure. Thermal energy transferred from the solid surface to the liquid drives the process. The form of Newton's Law of Cooling that describes this mode of heat transfer and quantifies the heat flux $\left(q^{\prime \prime}\right)$ is given by Equation 2.1 .

$$
q^{\prime \prime}=h\left(T_{\text {surf }}-T_{\text {sat }}\right)=h T_{e}
$$

Excess temperature $\left(T_{e}\right)$ is defined as the difference between the temperature of the surface $\left(T_{\text {surf }}\right)$ upon which boiling is occurring, and the saturation temperature $\left(T_{\text {sat }}\right)$ of the liquid. $T_{e}$ is required for the nucleation of bubbles and commencement of boiling. $h$ is defined as the boiling convection coefficient, or boiling heat transfer coefficient, and has units $\left[\mathrm{W} / \mathrm{m}^{2} \mathrm{~K}\right]$.

The boiling process is characterized by vapor bubbles forming upon the heated surface, then detaching to mix with the surrounding liquid. Vapor bubble formation, growth, and dynamics depend upon $T_{e}$, the nature of the surface upon which boiling is occurring, and the thermophysical properties of the fluid. The dynamics of vapor bubble formation can affect fluid motion near the surface, and consequently can affect the value of $h$ strongly.

Boiling may be classified either as subcooled or saturated. During subcooled boiling, the temperature of the liquid is below saturation, and bubbles may recondense in the liquid. Saturated boiling is characterized by a liquid temperature slightly above saturation, allowing buoyancy forces to propel the bubbles upward and away from the surface.

\subsection{Pool Boiling}

Pool boiling conditions refer to the boiling of stationary liquid. Motion near the surface is generally due to mixing associated with bubble formation and detachment. Pool boiling is generally assumed to occur upon an unconfined, nonporous surface. Saturated pool boiling has been studied extensively, and allows the application of Equation 2.1.

\subsubsection{Modes of Pool Boiling}

There are several modes, or regimes of pool boiling. Each is characterized by a different range of $q^{\prime \prime}$ and $T_{e}$.

The first mode is referred to as free convection boiling. Free convection boiling is associated with values of $T_{e}$ less than approximately $5^{\circ} \mathrm{C}$. In this regime there is 
insufficient vapor in contact with the liquid phase to cause boiling at the saturation temperature. Fluid motion in this regime is generally associated with free convection effects.

Nucleate boiling exists in the approximate $T_{e}$ range of $5^{\circ} \mathrm{C}$ to $30^{\circ} \mathrm{C}$. Isolated bubbles now form and separate from the boiling surface, initiating considerable fluid mixing, and substantially increasing $q "$ and $h$. For this reason, the nucleate boiling regime is one in which related engineering applications are designed to function. It is in this boiling regime that the maximum $h$ occurs; calculation is possible using Equation 2.1. The nucleate boiling regime is bounded by the so-called onset of nucleate boiling (ONB) and the critical heat flux $\left(q^{\prime \prime}{ }_{\max }\right)$.

Transition boiling, or unstable film boiling, corresponds to the approximate $T_{e}$ range of $30^{\circ} \mathrm{C}$ to $120^{\circ} \mathrm{C}$. In this regime, bubble formation is so rapid that a vapor blanket begins to form on the boiling surface. At any location on the surface, conditions may oscillate between nucleate and film boiling. Due to the increased vapor fraction, overall thermal conductivity decreases, which drives down $q^{\prime \prime}$ and $h$. The transition boiling regime is bounded by the $q^{\prime \prime}{ }_{\max }$ and so-called Leidenfrost point $\left(q^{\prime \prime}{ }_{\min }\right)$.

Film boiling exists for approximate values of $T_{e}$ above $120^{\circ} \mathrm{C}$. A vapor blanket covers the entire boiling surface at $q^{\prime \prime}{ }_{\min }$. As the surface temperature is increased, radiation through the vapor film becomes significant and $q^{\prime \prime}$ increases with increasing $T_{e}$.

\subsection{Effect of Asperities Upon Nucleation}

It has been demonstrated that the effect of surface roughness upon the relative values of $q^{\prime \prime}{ }_{\max }$ and $q^{\prime \prime}{ }_{\text {min }}$ is negligible. However, it has been observed that increased surface roughness can cause a large increase in $q^{\prime \prime}$ for the nucleate boiling regime (Berensen 1961). Similar research demonstrated that heat flux during nucleate boiling was proportional to excess temperature as well as the nucleation site density (Yamagata 1955). A roughened surface has numerous cavities that serve to trap vapor, providing more and larger sites for bubble growth. Therefore, the nucleation site density and heat flux can be considerably larger on a rough, rather than smooth surface.

The size and geometry of asperities influence the magnitude of $T_{e}$ required for nucleation. In a smaller, or sharper asperity, bubble initiation occurs at a lower $T_{e}$ due to expansion with a larger radii of curvature, afforded by the asperity geometry. It has been observed for boiling in porous media that the size of the pores relates to the thermodynamics of vaporization and the mobilization of vapor (Udell 1982).

\subsection{Boiling Curves}

A boiling curve illustrates the relationship between $T_{e}$ and $q^{\prime \prime}$ over a range of the boiling regimes discussed in Section 2.2.1. The conventional representation of the boiling curve is specific to pool boiling upon a nonporous surface. Research concerning pool boiling 
upon a porous surface produced a variation of the conventional boiling curve (Kovalev 1987). Figure 2-1 presents this boiling curve comparison.

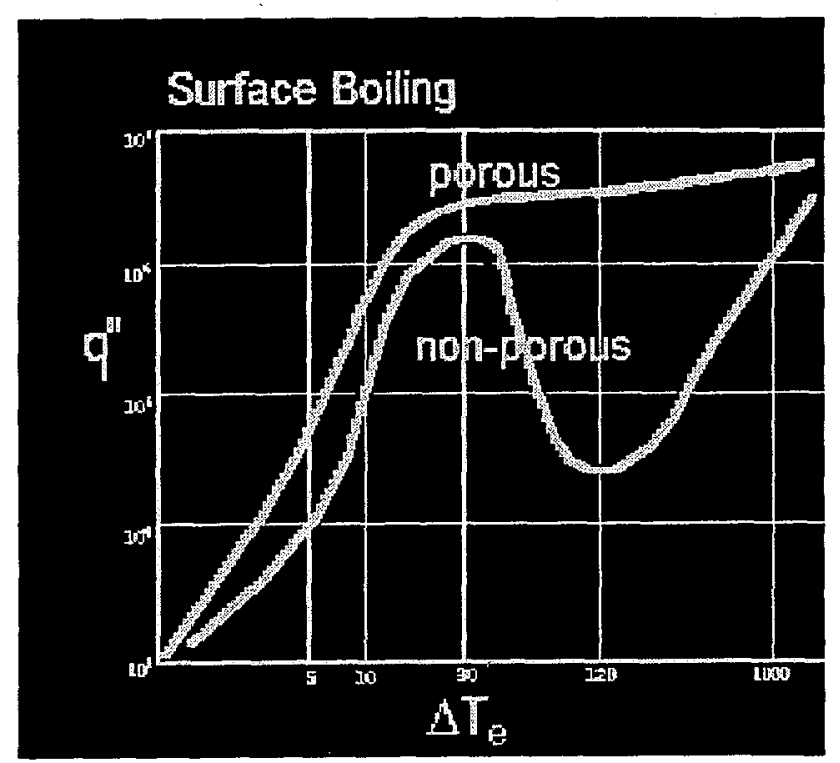

Figure 2-1: Boiling Curve Comparison (Kovalev 1987)

The obvious difference between porous and nonporous boiling curves, is the absence of a $q^{\prime \prime}$ decrease at high $T_{e}$ for porous surface boiling. It is postulated in this research that because nucleation and boiling may initiate within the pores and asperities of a porous surface, the vapor blanket observed on nonporous surfaces does not form.

\subsection{Boiling On a Porous Surface and Calculation of $\boldsymbol{h}$}

This research focused upon the differences in boiling on porous and nonporous surfaces. Previous work suggests that nucleation on a porous surface may in fact occur within the pores and asperities, and therefore below the surface. Defining the value of heat flux with boiling on a surface involves relating conductive heat transfer and boiling convective heat transfer. For boiling on a nonporous surface, this transition point is defined as the surface upon which boiling occurs. It was hypothesized in this research that this transition point exists not on the visible surface, but a distance below the surface at which nucleation commences. The plane upon which nucleation begins is likely a function of the permeability of the porous material, as well as it's pore size and pore geometry.

Therefore, it follows that to employ established relationships for quantifying boiling heat flux on a nonporous surface, some modifications must be made. For the purposes of this research, heat flux was defined by Equation 2.2 .

$$
q^{\prime \prime}=h\left(T_{\text {surf }}-T_{\text {sat }}\right)=h T_{e}
$$

$T_{\text {surf }}$ was redefined as the plane upon which nucleation occurs. For pure water at a pressure of $1 \mathrm{~atm}, T_{\text {surf }}$ was assigned a value of $100^{\circ} \mathrm{C} . T_{\text {sat }}$ remained the saturated 
temperature of the liquid, in either a saturated or subcooled boiling regime. Calculation of a boiling heat transfer coefficient for a porous surface was calculated using Equation 2.3 .

$$
h=q^{\prime \prime} /\left(T_{\text {surf }}-T_{\text {sat }}\right)=q^{\prime \prime} / T_{e}
$$




\section{Boiling On a Confined Nonporous Surface}

\subsection{Boiling In a Fracture Bounded By Aluminum}

Much research has been conducted in the past on pool boiling on a nonporous surface. Heat transfer relationships for this scenario have been proven for unconfined boiling. A departure from these earlier approaches was necessary to examine the phenomena of confined boiling in a fracture bounded by a nonporous material. Therefore, an apparatus designed and used in previous experiments (Duteaux, 1998) was modified to achieve these experimental goals.

\subsection{Experimental Preparation}

The existing experimental apparatus required modification for this genre of experiments. Additionally, preparation of the experimental material itself was necessary.

\subsubsection{Experimental Apparatus}

The apparatus consisted of a 400-Watt Full Sheath Disc Heater which was encased in fiber board insulation on all sides but the top. On the heater surface, a disk of experimental material was positioned, also insulated with a ring of insulation. Three thin, stainless steel shims $0.508 \mathrm{~mm}$ in thickness separated this experimental material from a glass disk, positioned on top. Through a hole drilled in the center of this glass disk, water was injected into this simulated fracture, heated from below by the heater, and allowed to boil on the surface of the experimental material. An outer stainless steel structure held these components in place. Figure 3-1 depicts the experimental apparatus and orientation. 

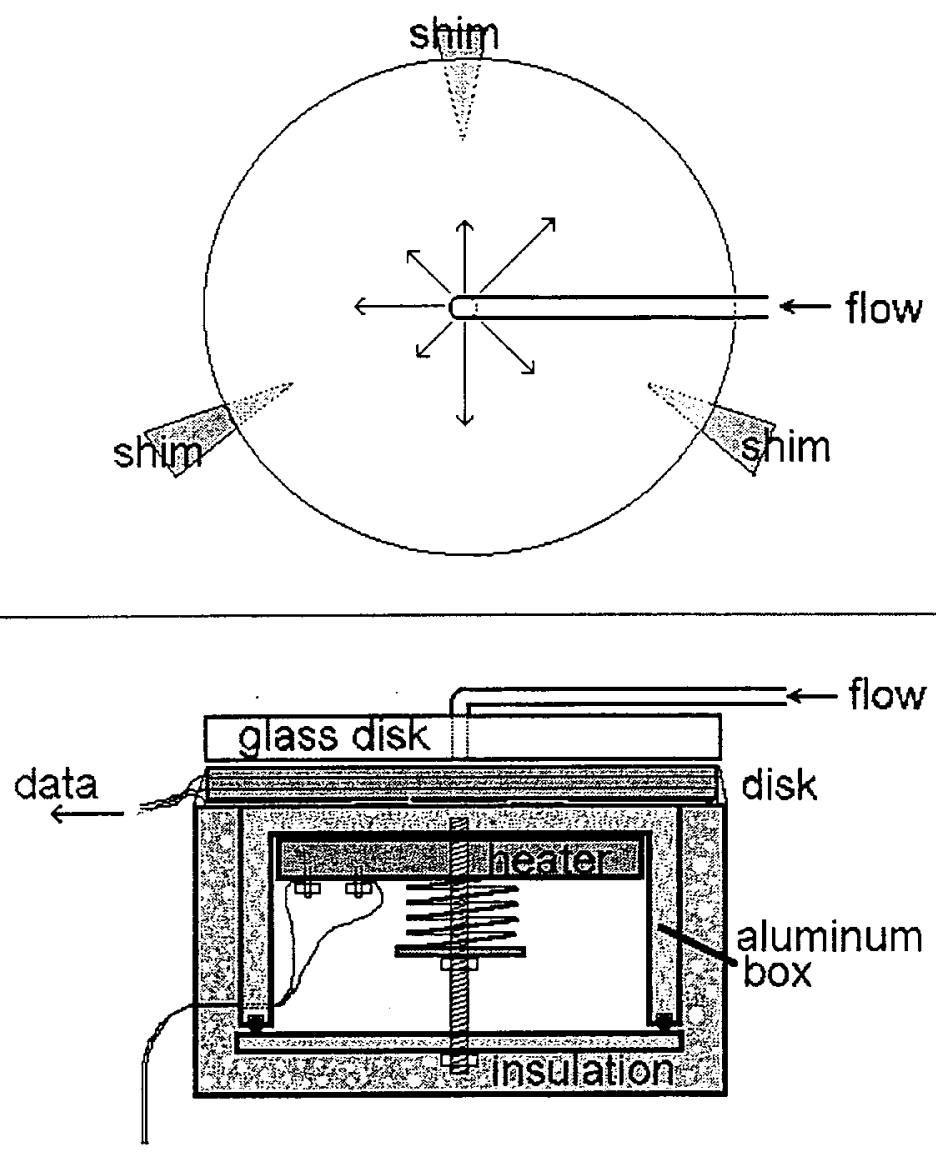

Figure 3-1: Heat flux-Temperature gradient measurement experimental apparatus

(Duteaux, 1998)

Two J-type thermocouples and two heat flux sensors were oriented in machined recesses on the surface of the heater, at the junction of the heater and the experimental material. Eight T-type thermocouples were installed in the experimental material itself to monitor developing temperature gradients. Two J-type thermocouples were oriented in the fracture aperture to record the saturation temperature associated with boiling in the fracture.

The injection of water into the fracture was controlled with a small positive displacement pump, which allowed application of a range of flow rates. The water used in the experiment was deionized water which was boiled as a de-gassing procedure. The water was then passed through a length of tygon tubing submerged in a large receptacle of cool water. After passing through the pump, the water was directed through a copper coil submerged in a heated bath. This allowed the deaerated water to be warmed closer to saturation temperature before injection into the fracture. Temperature and heat flux data that developed with boiling in the fracture was recorded and observed using LabView data acquisition software. A schematic of the experimental setup is presented in Figure $3-2$. 


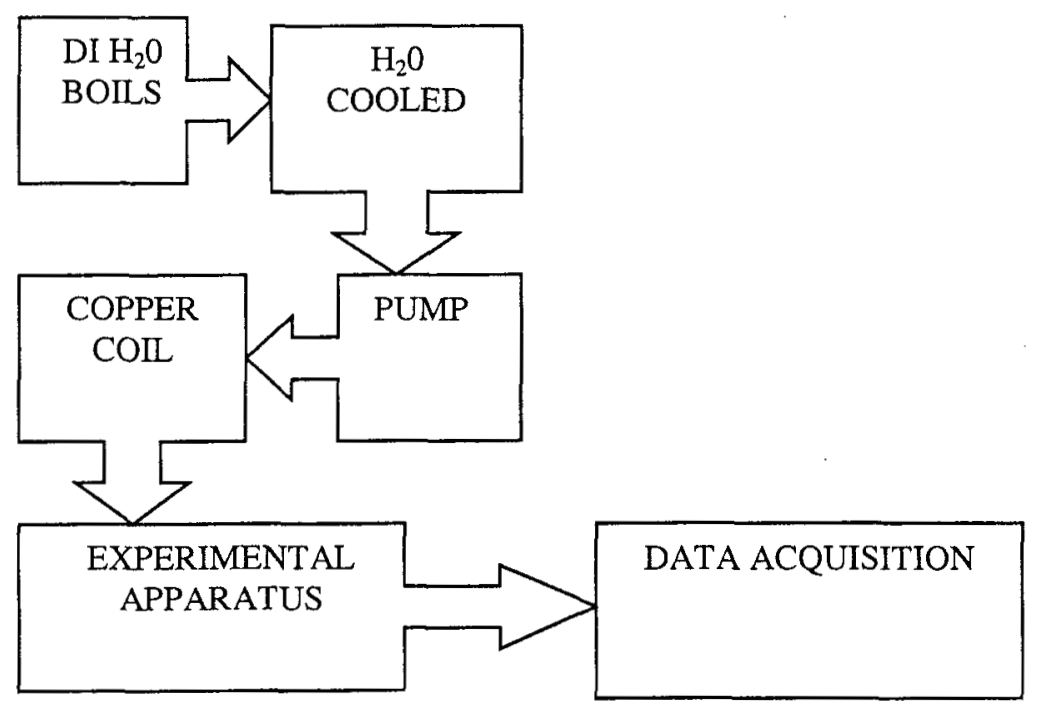

Figure 2-2: Experimental Schematic

\subsubsection{Experimental Material}

The nonporous aluminum employed in this experiment required proper sizing and the installation of thermocouple holes. A piece of 6061 aluminum was machined into a circular disk form, approximately $8.9 \mathrm{~cm}$ in diameter and $2.5 \mathrm{~cm}$ thick. Eight holes were drilled from the outer edge of the disk toward the center to accommodate $1.0 \mathrm{~mm}$ diameter T-type thermocouples.

Each of the holes were offset $15^{\circ}$ from the next, and extended to within $1.5 \mathrm{~cm}$ of the disk center. Thus, both the heat flux and temperature gradient normal to the surface of the aluminum were measured near the center of the fracture. The hole diameter was only slightly greater than the thermocouples to insure a tight fit and good thermal contact.

Two holes were installed at each of four prescribed depths from the top of the disk. These depths were 5.1, 10.2, 15.3, and $20.4 \mathrm{~mm}$ from the top (fracture surface). The orientation of drilled holes are presented in Figure 3-3. 

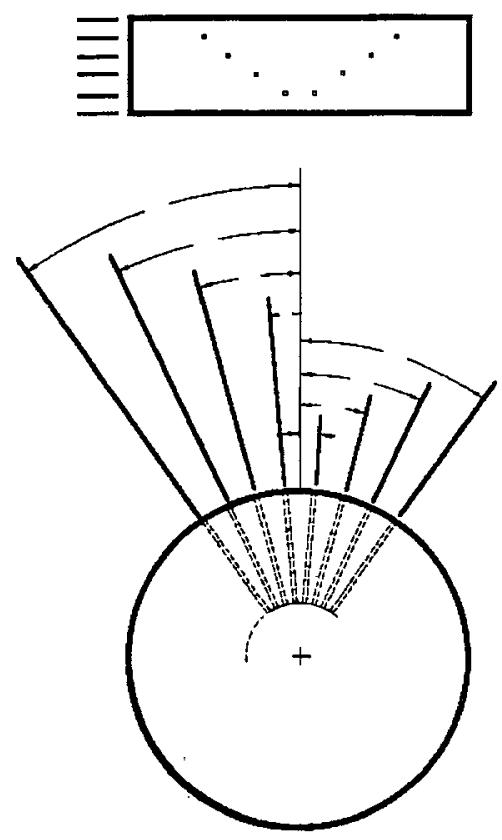

Figure 3-3: Orientation of drilled thermocouple holes in aluminum disk

Calculation of the boiling convection coefficient using the unconfined pool boiling relationship, requires that the surface temperature on the top of the aluminum disk and in the fracture be known. In the first two of three experiments which utilized the aluminum disk, this was calculated by linear interpolation of the linear temperature gradient which developed axially in the aluminum disk. To achieve a tangible value of $T_{\text {surf }}$ in the third aluminum experiment, thin 12.5 micron cementable thermocouples were installed on the surface of the disk. These thin T-type thermocouples were oriented $120^{\circ}$ from each other, $1.5 \mathrm{~cm}$ from the center of the disk. They were bonded to the surface using a cement of high thermal conductivity.

A ring of fiber board insulation was placed around the aluminum disk to restrain heat flow. The insulation encasing the heater, and the ring surrounding the aluminum disk were coated with a layer of high temperature epoxy to repel water that exited the fracture during the experiment. Additional gaps were closed with RTV high temperature silicone for waterproofing purposes.

In order to obtain sufficiently good thermal contact, a heat sink compound was applied at the interface of aluminum and heater surface.

\subsection{Experimental Procedure and Conditions}

As indicated in Figure 3-2, deionized, deaerated water was supplied to a small positive displacement pump. The pump was adjusted to supply discrete rates of 15, 30, and 45 $\mathrm{ml} / \mathrm{min}$. This water was heated to approximately $70^{\circ} \mathrm{C}$ by flowing through a copper coil 
immersed in a heated water bath. The water was then injected through the center of the glass disk and into the fracture. The fracture aperture was fixed at $0.508 \mathrm{~mm}$.

Power was supplied to the heater using a variac, and the voltage and current monitored with digital multimeters. Power was slowly increased until boiling began at an injection rate of $45 \mathrm{ml} / \mathrm{min}$. It could be assumed that this was the minimum power at which the maximum flow rate would allow boiling in the fracture. Maintaining this initial power, developing temperature gradients were allowed to achieve steady state, and temperature and heat flux data were recorded. Data were collected with the outer edge of the apparatus exposed to atmospheric pressure. The thermocouples installed in the disk recorded the temperature gradients that developed as water flashed to steam in the fracture. The boiling regime and behavior were observed through the glass disk, and the vapor fraction estimated. The pump was then adjusted to supply 30 and $15 \mathrm{ml} / \mathrm{min}$ injection rates, during which the same sequence was followed.

Four power inputs $(240,285,350$, and 480 Watts) were supplied by the heater and were maintained at those levels for each of the three prescribed flow rates. Once steady state conditions were achieved, data was collected. The intent of multiple power inputs was to produce several measurements of the excess temperature at different values of heat flux. These data could be compared to the established boiling curve for pool boiling conditions, and infer differences related to a confined boiling regime.

\subsection{Experimental Observations and Results}

The temperature data from each thermocouple that was collected upon steady state was averaged over the time interval of collection. Because two thermocouples existed at each depth within the aluminum (distance from the fracture), these average values were again averaged to obtain the steady state temperature for that position. The temperature gradients that developed across the aluminum disk with boiling in the fracture are depicted in Figure 3-4. 


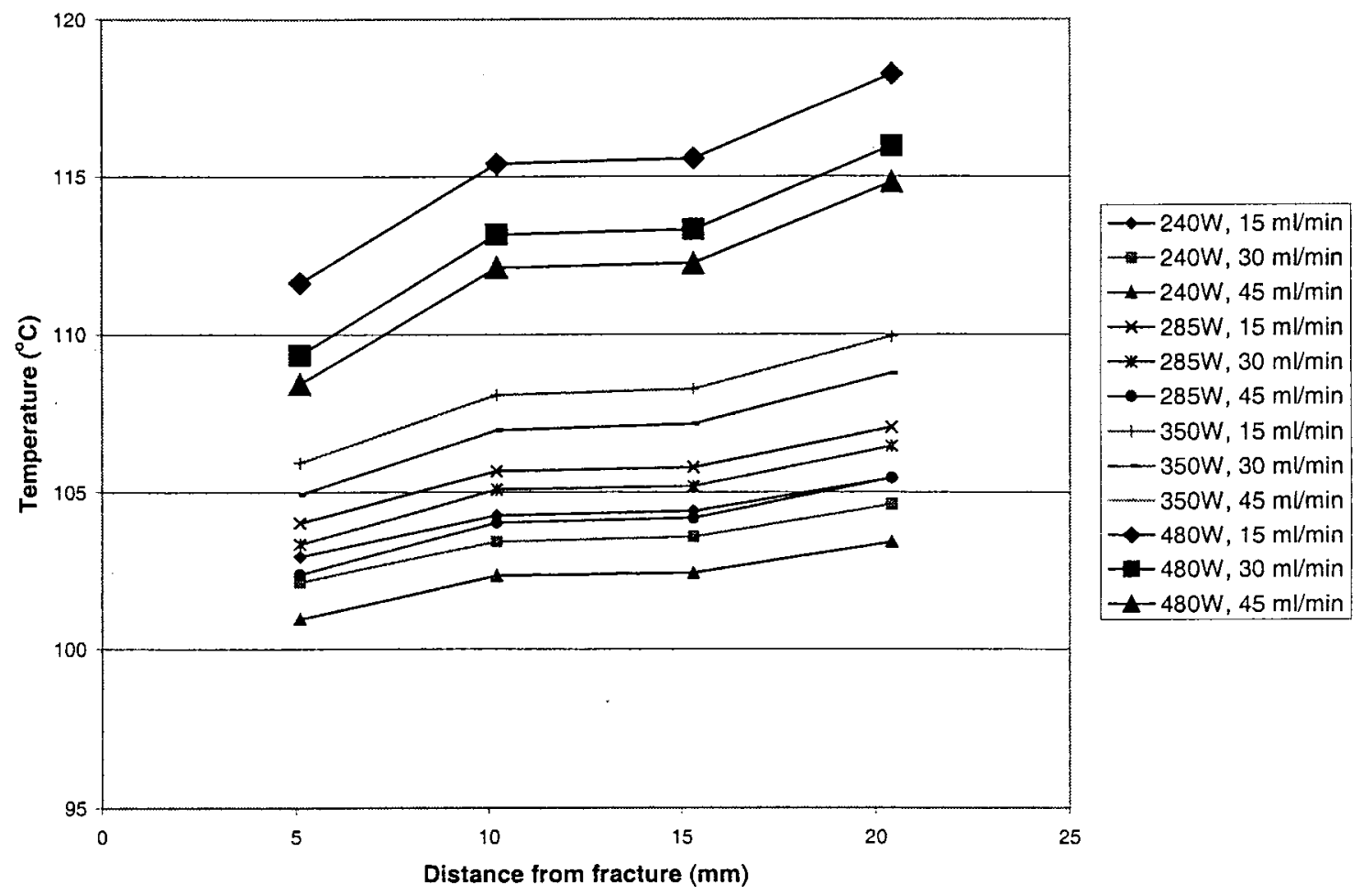

Figure 3-4: Temperature gradient for varying powers and injection rates - Aluminum Experiment

Both the heat flux sensors and cementable surface thermocouples failed to provide reliable data. Therefore, as was done in experiments that did not utilize the cementable thermocouples, values of $q^{\prime \prime}$ were calculated using Fourier's Law of heat conduction and the thermal conductivity of 6061 aluminum $(237 \mathrm{~W} / \mathrm{mK})$. The $d T / d x$ used was that between thermocouples 1 ( $5.1 \mathrm{~mm}$ below surface) and $4(20.4 \mathrm{~mm}$ below surface). Equation 3.1 indicates Fourier's Law.

$$
\begin{aligned}
q^{\prime \prime} & =k d T / d x \\
{[\mathrm{~W}] } & =[\mathrm{W} / \mathrm{mK}]^{*}[\mathrm{~K} / \mathrm{m}]
\end{aligned}
$$

The excess temperature $T_{e}$ was determined using equation 2.1, which requires the $T_{\text {surf }}$ and $T_{\text {sat. }} . T_{\text {sat }}$ was measured by the average value of two J-type thermocouples in the fracture during the experiment. The surface temperature of the aluminum upon which boiling occurred was calculated using by extrapolating the linear temperature gradient that developed across the disk. This trend was extended to the surface of the disk, or wall of the fracture.

Using the values of heat flux and excess temperature for each power and flow rate combination, the boiling convection coefficient $h$ was calculated using Equation 2.3. Table 3-1 presents the results of this experiment. 
Table 3-1: Results and Observations - Aluminum Experiment

\begin{tabular}{|cccccccc|}
\hline $\begin{array}{c}\text { Power } \\
\text { (Watts) }\end{array}$ & $\begin{array}{c}\text { Flow Rate } \\
(\mathbf{m} / / \mathbf{m i n})\end{array}$ & $\begin{array}{c}\text { Fraction } \\
(\%)\end{array}$ & $\begin{array}{c}\mathbf{T}_{\text {surf }} \\
\left({ }^{\circ} \mathbf{C}\right)\end{array}$ & $\begin{array}{c}\mathbf{T}_{\text {sat }} \\
\left({ }^{\circ} \mathbf{C}\right)\end{array}$ & $\begin{array}{c}\mathbf{T}_{\mathbf{e}} \\
\left({ }^{\circ} \mathbf{C}\right)\end{array}$ & $\begin{array}{c}\mathbf{q}^{\prime \prime} \\
\left(\mathbf{W} / \mathbf{m}^{2}\right)\end{array}$ & $\begin{array}{c}\mathbf{h} \\
\left(\mathbf{W} / \mathbf{m}^{2} \mathbf{K}\right)\end{array}$ \\
\hline 240 & 15 & $30-40$ & 102.35 & 99.91 & 2.44 & 38,855 & 15,897 \\
& 30 & $20-30$ & 101.54 & 99.27 & 2.27 & 38,535 & 16,983 \\
& 45 & $10-20$ & 100.42 & 95.59 & 4.83 & 38,140 & 7,894 \\
& & & & & & & \\
285 & 15 & 80 & 103.34 & 99.81 & 3.53 & 46,888 & 13,276 \\
& 30 & $50-60$ & 102.65 & 99.07 & 3.58 & 48,496 & 13,564 \\
& 45 & $30-40$ & 101.67 & 97.43 & 4.24 & 47,671 & 11,244 \\
& & & & & & & \\
& 15 & 90 & 105.02 & 100.28 & 4.74 & 61,656 & 13,011 \\
& 30 & $40-50$ & 104.03 & 99.29 & 4.74 & 59,405 & 12,543 \\
& 45 & 50 & 103.03 & 98.63 & 4.40 & 60,202 & 13,686 \\
& & & & & & & \\
& 15 & $90-95$ & 110.20 & 100.93 & 9.27 & 102,756 & 11,084 \\
& 30 & 80 & 107.94 & 99.82 & 8.12 & 102,548 & 12,635 \\
& 45 & 50 & 107.07 & 99.38 & 7.69 & 98,899 & 12,862 \\
\hline
\end{tabular}

As summarized in Table 3-1, the vapor fraction within the fracture increased with increasing power supplied by the heater. Additionally, vapor fraction decreased with increasing injection rate. Boiling flow in general, but especially at higher powers and lower injection rates, was violent and highly chaotic. Preferred nucleation sites were evident on the aluminum surface. It appeared that capillary pressure affected the boiling regime by preventing the advance of the liquid phase in regions dominated by the vapor phase.

In Figures 3-5 through 3-7, heat flux, excess temperature, and boiling convection coefficient data are graphed for each of the four power inputs. The data collected for $240 \mathrm{~W}$ and $45 \mathrm{ml} / \mathrm{min}$ departs from the expected trend, and is therefore considered anomalous. This data point pertains to the measured excess temperature, and affects the calculated value of $h$. 


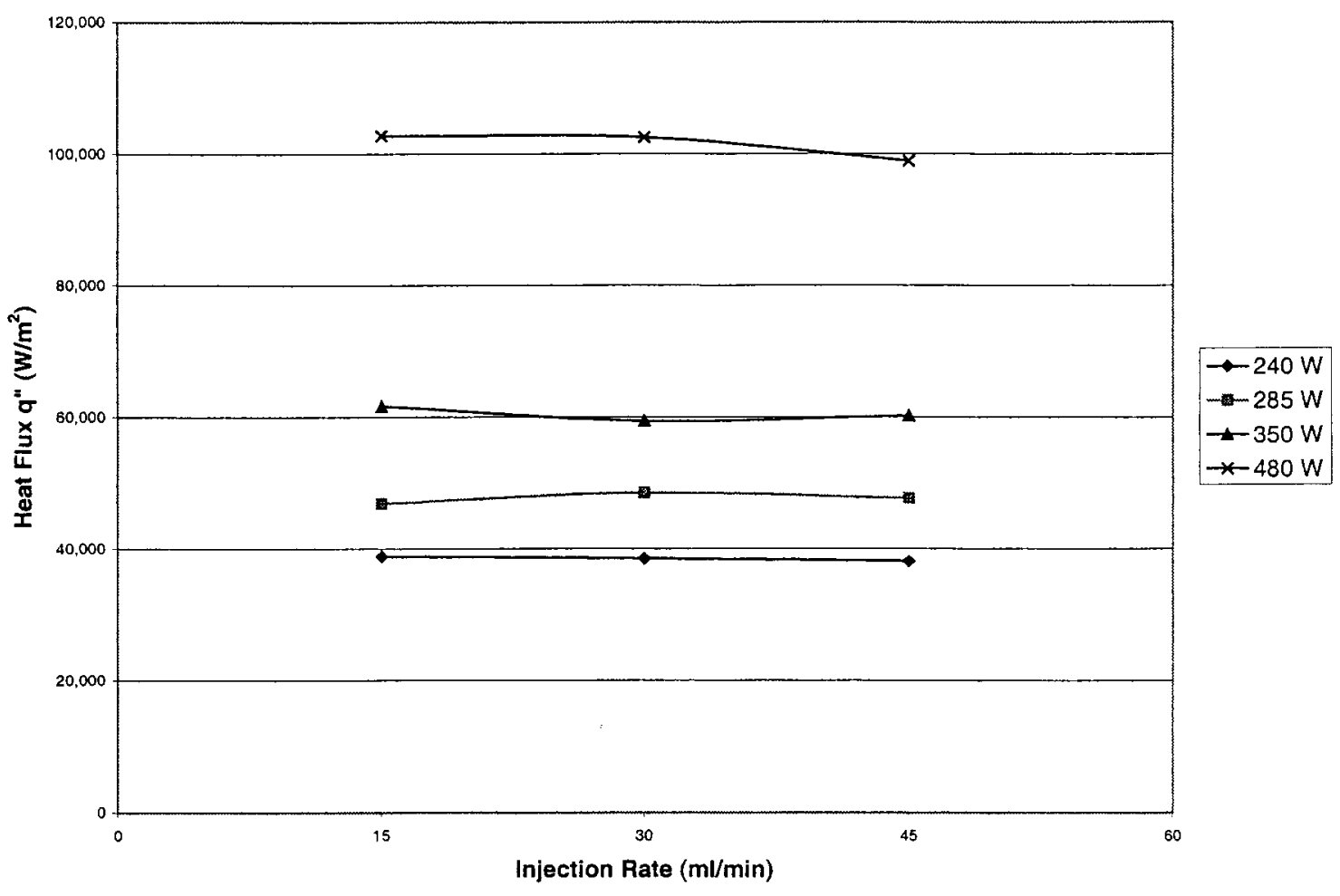

Figure 3-5: Heat flux variance with power and flow rate

It is clear from Figure 3-5 that heat flux is not a function of flow rate on a confined nonporous surface. 


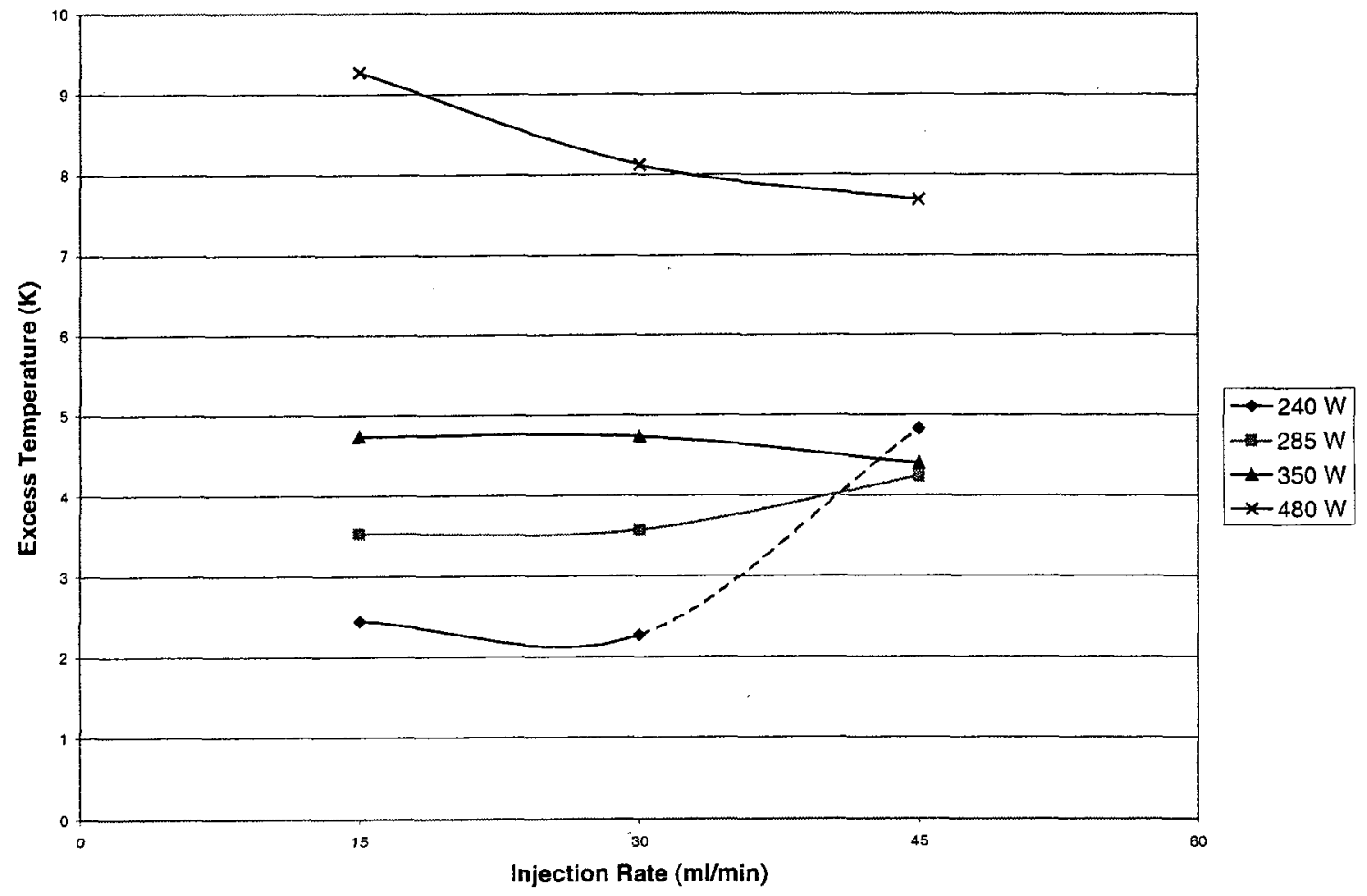

Figure 3-6: Excess temperature variance with power and flow rate

Essentially no trends are apparent in Figure 3-6, indicating that $T_{e}$ is not a function of injection rate on a confined nonporous surface. The anomalous data point and associated trend is represented in Figure 3-6 as a dashed line. 


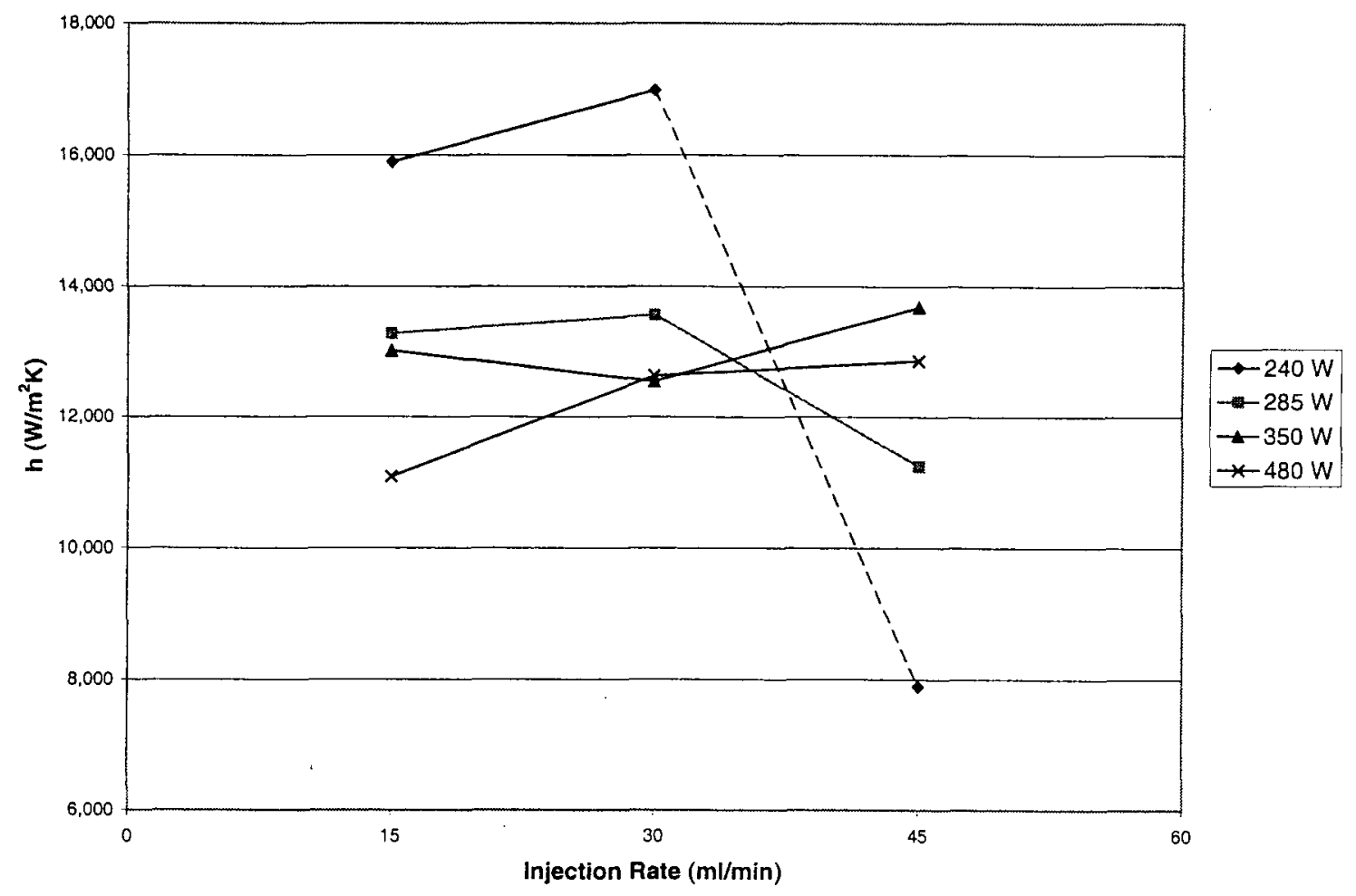

Figure 3-7: Boiling convection coefficient variance with power and flow rate

Essentially no trends are apparent in Figure 3-7, indicating that $h$ is not a function of injection rate on a confined nonporous surface. The anomalous data point and associated trend is represented in Figure 3-6 as a dashed line.

\subsection{Discussion}

For boiling on a confined nonporous surface, it appears the $q^{\prime \prime}, T_{e}$, and $h$ values are not strongly coupled to the injection rate. Therefore, it is the heat supplied to the surface that dictates the magnitude of the heat flux, excess temperature, and therefore the magnitude of the boiling convection coefficient.

Comparison of the pool boiling curve to data generated during this experiment was not possible because of the relatively low values of $T_{e}$. A $T_{e}$ of around $30 \mathrm{~K}$, rather than the experimental maximum of about $10 \mathrm{~K}$, would have provided data for comparison. The maximum wattage of $480 \mathrm{~W}$ was the maximum capability of the heater used the experiment. A more powerful heater would be required to obtain higher values of $T_{e}$.

However, based upon pool boiling standards, an approximate $T_{e}$ value of $10 \mathrm{~K}$ indicates achievement of the nucleate boiling regime, and perhaps a near maximum value of $h$. 


\section{Boiling On a Confined Highly Porous Surface}

\subsection{Boiling In a Fracture Bounded by Berea Sandstone}

To provide stark contrast to the experimental investigation of boiling in a fracture bounded by nonporous, impermeable aluminum, the next experiment utilized highly porous and permeable sandstone.

\subsection{Experimental Preparation}

The experimental apparatus depicted in Figure 3-1 was used without modification for the sandstone experiment. Some differences existed between the preparation of the aluminum disk and the sandstone disk.

\subsubsection{Experimental Material}

The highly porous and permeable sandstone employed in this experiment required proper sizing and the installation of thermocouple holes. A disk of sandstone was cut from a core of Berea sandstone using a diamond-tipped rock saw. The two sides of the disk were rendered parallel using a surface grinder. The final dimensions of the sandstone disk were approximately $8.9 \mathrm{~cm}$ in diameter, and $2.0 \mathrm{~cm}$ thick. Eight holes were drilled from the outer edge of the disk toward the center to accommodate $1.0 \mathrm{~mm}$ diameter T-type thermocouples.

As with the aluminum disk, each of the holes were offset $15^{\circ}$ from the next, and extended to within $1.5 \mathrm{~cm}$ of the disk center. Thus, both the heat flux and temperature gradient normal to the surface of the sandstone were measured near the center of the fracture. The hole diameter was only slightly greater than the thermocouples to insure a tight fit and good thermal contact.

Two holes were installed at each of four prescribed depths from the top of the disk. These depths were $3.0,6.5,10.0$, and $13.5 \mathrm{~mm}$ from the top (fracture surface). The orientation of drilled holes are presented in Figure 4-1. 


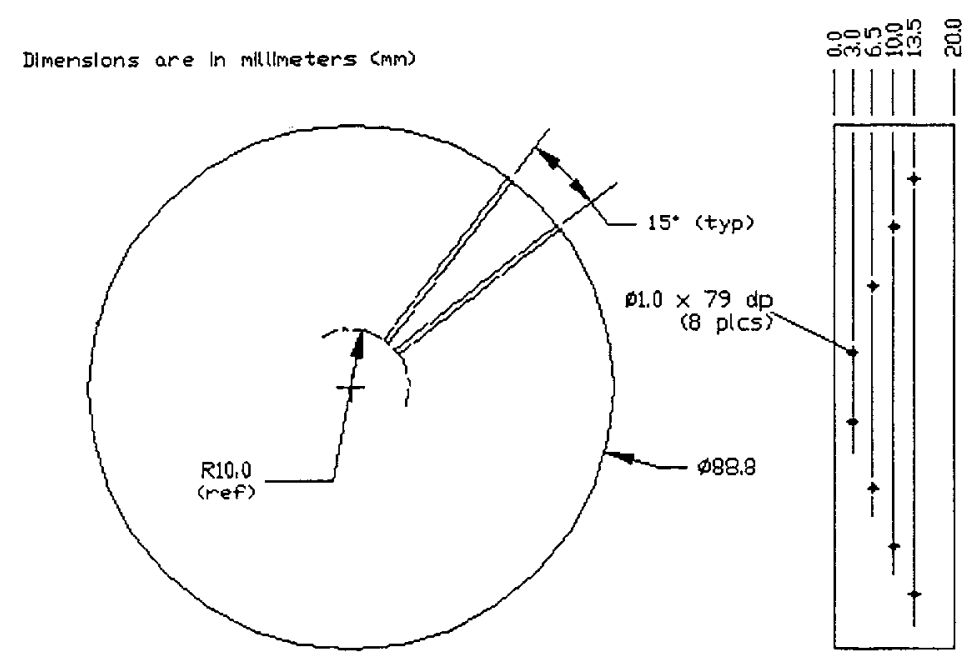

Figure 4-1: Dimensions and thermocouple orientation in sandstone disk

A ring of fiber board insulation was placed around the sandstone disk to restrain radial heat flow. The top of the insulating ring was slightly lower than the top of the sandstone disk, allowing water to exit the fracture unchecked. The ring surrounding the sandstone disk was coated with a layer of high temperature epoxy to repel water that exited the fracture during the experiment. Additional gaps were closed with RTV high temperature silicone for waterproofing purposes.

The outer edge of the rock was sealed with epoxy and silicone to prohibit radial liquid flow within the rock and to restrain radial heat conduction. In order to obtain sufficiently good thermal contact, a heat sink compound was applied at the interface of sandstone and the heater surface. The rock surface was coated on the heater side with a thin film of high temperature epoxy to prevent the spontaneous imbibition of oil from the heat sink compound into the rock.

\subsection{Experimental Procedure and Conditions}

As indicated in Figure 3-2, deionized, deaerated water was supplied to a small positive displacement pump. The pump was adjusted to supply discrete rates of 15,30 , and 60 $\mathrm{ml} / \mathrm{min}$. This water was heated to approximately $70^{\circ} \mathrm{C}$ by flowing through a copper coil immersed in a heated water bath. The water was then injected through the center of the glass disk and into the fracture. The fracture aperture was fixed at $0.508 \mathrm{~mm}$.

As during the aluminum experiment, power was supplied to the heater using a variac, and the voltage and current monitored with digital multimeters. Power was slowly increased until boiling began at an injection rate of $60 \mathrm{ml} / \mathrm{min}$. It could be assumed that this was the minimum power at which the maximum flow rate would allow boiling in the fracture. 
Holding this initial power, developing temperature gradients were allowed to achieve steady state, and temperature and heat flux data were recorded. Data were collected with the outer edge of the apparatus exposed to atmospheric pressure. The thermocouples installed in the disk recorded the temperature gradients that developed as water flashed to steam in the fracture, and boiled within the rock matrix.

The boiling regime and behavior were observed through the glass disk, and the vapor fraction estimated. The pump was then adjusted to supply 30 and $15 \mathrm{ml} / \mathrm{min}$ injection rates, during which the same sequence was followed. This procedure was employed using only one power input from the heater $(240 \mathrm{~W})$.

\subsection{Experimental Observations and Results}

The temperature data from each thermocouple that was collected upon steady state was averaged over the time interval of collection. Because two thermocouples existed at each depth within the sandstone (distance from the fracture), these average values were again averaged to obtain the steady state temperature for that position. Figure 4-2 presents the temperature gradients that developed within the sandstone for each of the injection rates.

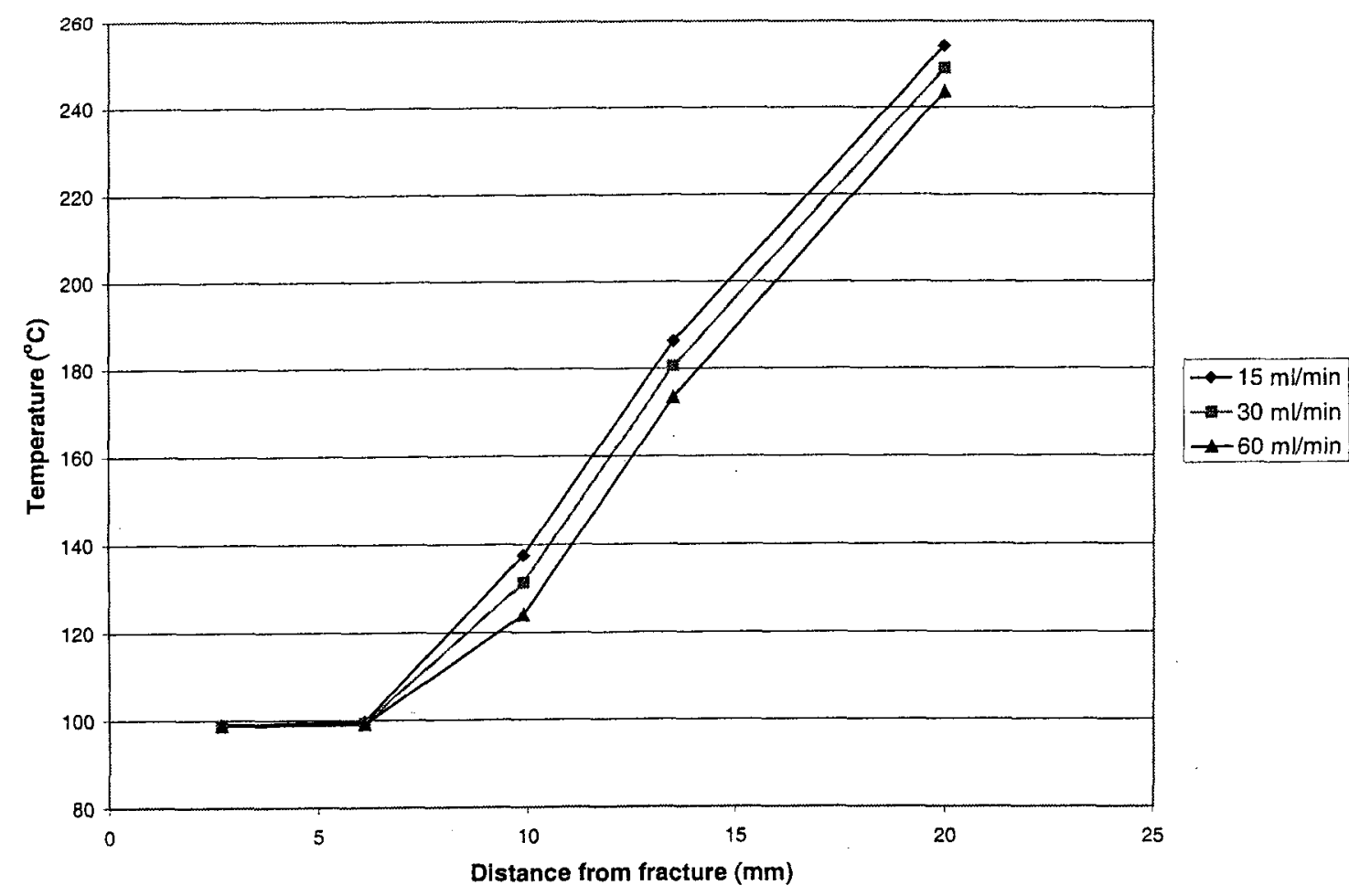

Figure 4-2: Temperature Gradients for Three Flow Rates - Sandstone Experiment

The heat flux sensors again failed to provide reliable data. Therefore, as was done previously, values of $q$ " were calculated using Fourier's Law of heat conduction and an 
average thermal conductivity of Berea sandstone $(3.5 \mathrm{~W} / \mathrm{mK})$. The $d T / d x$ used was that between thermocouples $2(6.1 \mathrm{~mm}$ below surface) and 4 (13.5 mm below surface).

The slope of the temperature gradient between thermocouples $1(2.7 \mathrm{~mm}$ below the surface) and 2 (6.1 $\mathrm{mm}$ below the surface) was used to determine the intercept with $100^{\circ} \mathrm{C}$, and therefore the depth at which boiling occurred in the sandstone.

The excess temperature $T_{e}$ was determined using the values of $T_{\text {surf }}$ and $T_{\text {sat }} . T_{\text {sat }}$ was measured by the two J-type thermocouples in the fracture during the experiment. $T_{\text {surf }}$ existed at the calculated depth of boiling in the rock matrix, and was assigned a value of $100^{\circ} \mathrm{C}$. The porous surface boiling value of $T_{e}$ at each flow rate was essentially $100^{\circ} \mathrm{C}$ $T_{\text {sat }}$.

Using the values of heat flux and excess temperature for each flow rate combination, the boiling convection coefficient $h$ was calculated. Table $4-1$ presents the results of this experiment.

Table 4-1: Results and Observations - Sandstone Experiment

\begin{tabular}{|ccccccccc|}
\hline $\begin{array}{c}\text { Power } \\
\text { (Watts) }\end{array}$ & $\begin{array}{c}\text { Flow Rate } \\
(\mathbf{m l} / \mathbf{m i n})\end{array}$ & $\begin{array}{c}\text { Fraction } \\
(\%)\end{array}$ & $\begin{array}{c}\text { Boiling Depth } \\
(\mathbf{m m})\end{array}$ & $\begin{array}{c}\mathbf{T}_{\text {surf }} \\
\left({ }^{\circ} \mathbf{C}\right)\end{array}$ & $\begin{array}{c}\mathbf{T}_{\text {sat }} \\
\left({ }^{\circ} \mathbf{C}\right)\end{array}$ & $\begin{array}{c}\mathbf{T}_{\mathbf{e}} \\
\left({ }^{\circ} \mathbf{C}\right)\end{array}$ & $\begin{array}{c}\mathbf{q}^{\prime \prime} \\
\left(\mathbf{W} / \mathbf{m}^{2}\right)\end{array}$ & $\begin{array}{c}\mathbf{h} \\
\left(\mathbf{W} / \mathbf{m}^{2} \mathbf{K}\right)\end{array}$ \\
\hline 240 & 15 & 95 & 7.21 & 100 & 97.13 & 2.87 & 40,933 & 14,248 \\
& 30 & 85 & 11.51 & 100 & 95.21 & 4.79 & 38,441 & 8,022 \\
& 60 & 35 & 15.07 & 100 & 94.37 & 5.63 & 35,145 & 6,246 \\
\hline
\end{tabular}

As summarized in Table 4-1, vapor fraction within the fracture decreased with increasing injection rate. Boiling flow in general was violent and highly chaotic. It appeared that water injected at the center of the disk penetrated the sandstone matrix before boiling, then after flowing radially through the rock, exited as boiling flow near the radial edge. Therefore, most of the observed boiling was near the edge of the rock and fracture. However, preferred nucleation sites were still evident on the sandstone surface. Specific regions of the surface were predominantly occupied by the vapor, rather than liquid phase.

In Figures 4-3 through 4-4, heat flux, excess temperature, and boiling convection coefficient data are graphed over each of the three flow rates. 


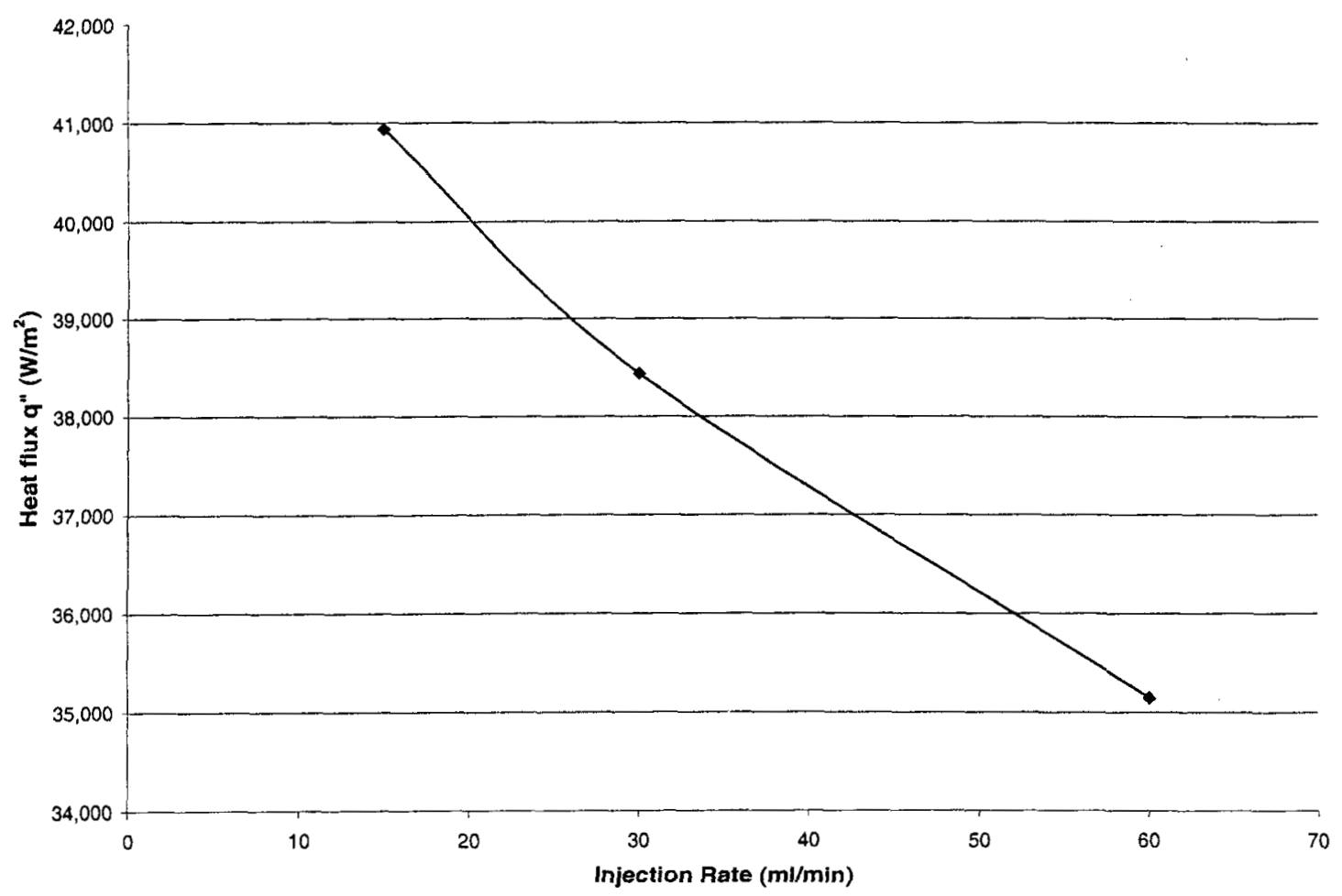

Figure 4-3: Heat flux variance with injection rate - Sandstone Experiment

A near linear decrease in $q^{\prime \prime}$ is observed with increasing injection rate. 


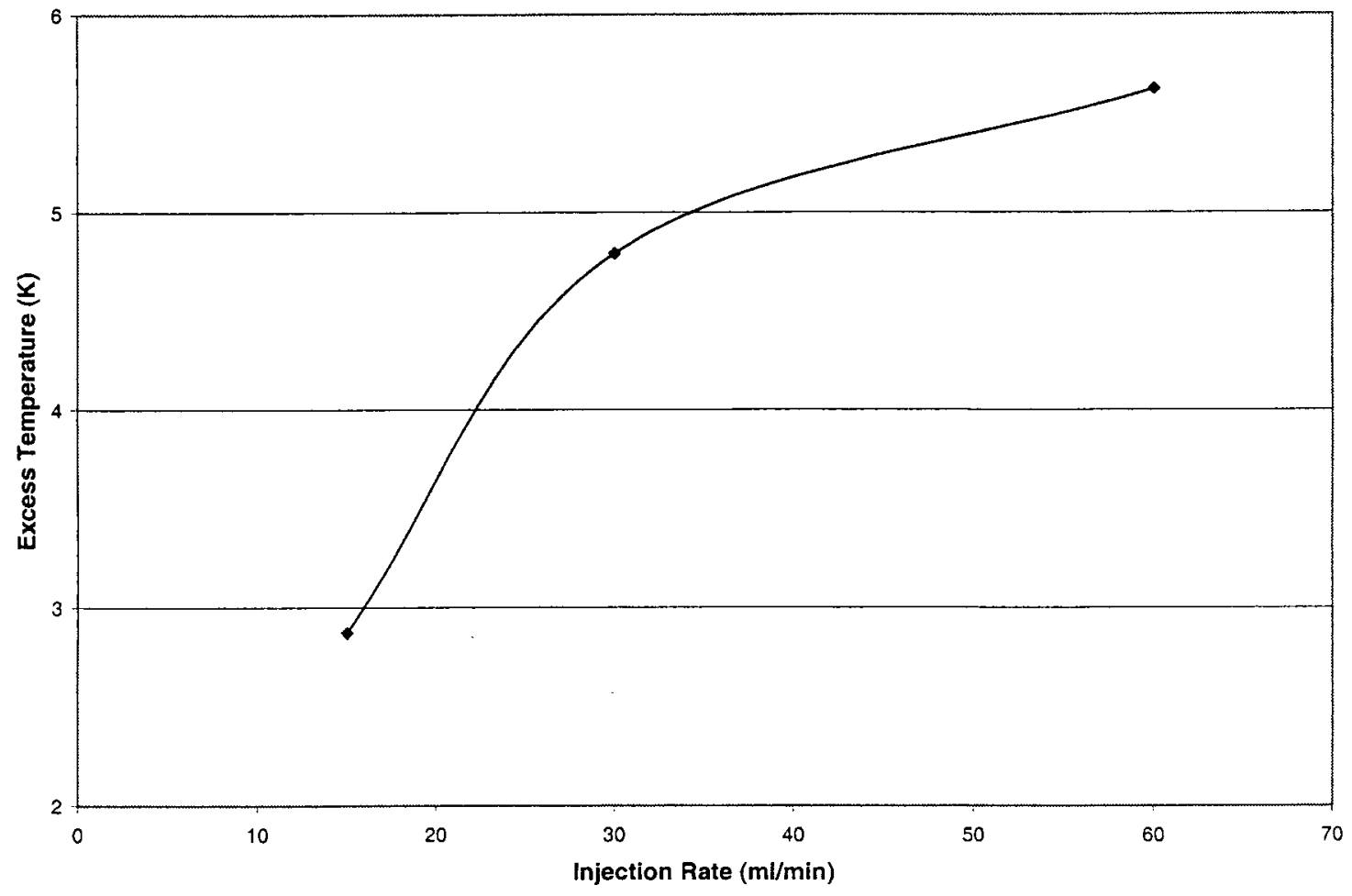

Figure 4-4: Excess temperature variance with injection rate - Sandstone Experiment

Decreasing $T_{\text {sat }}$ with increasing injection rate drives the increase in $T_{e}$. 


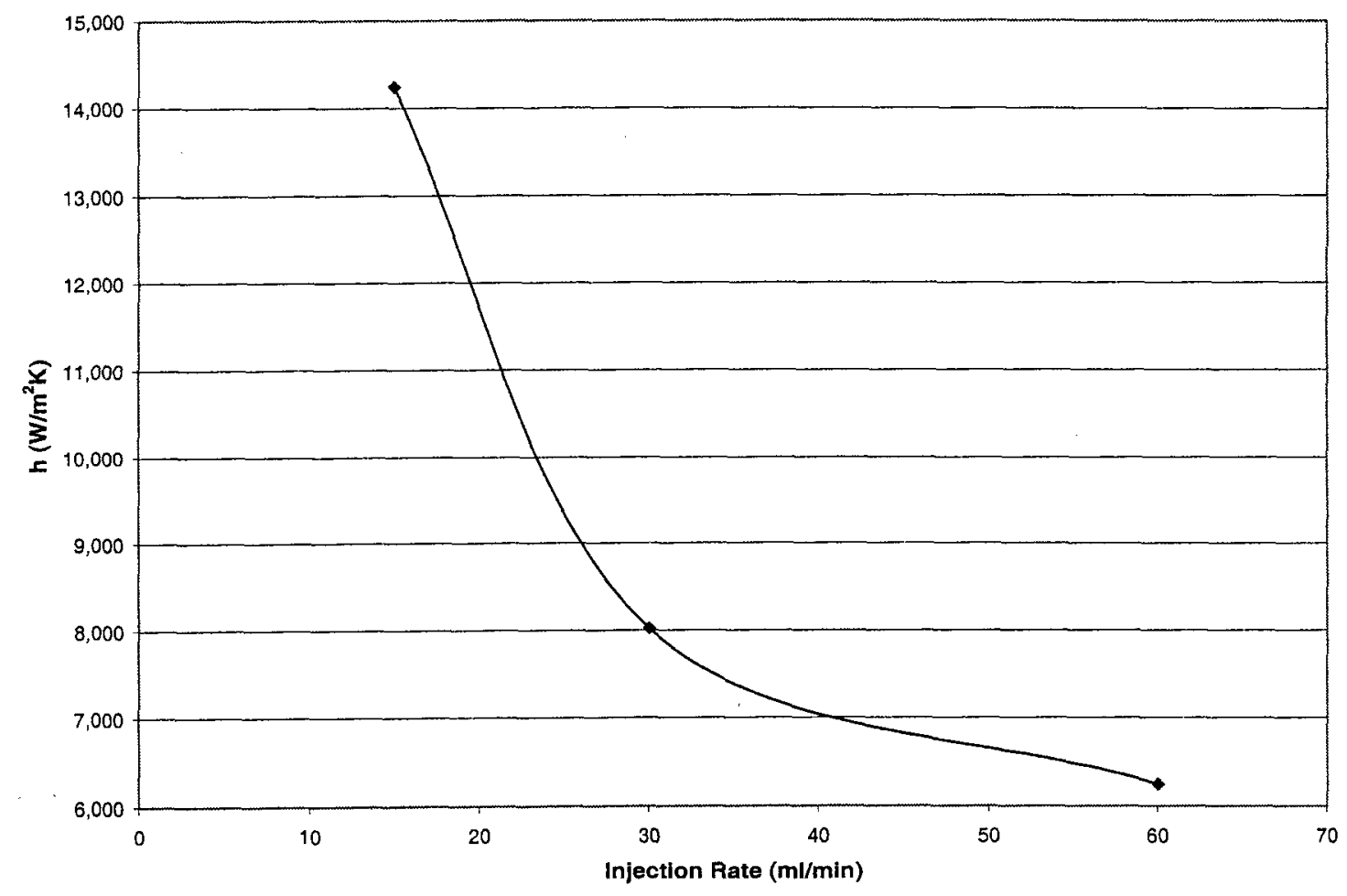

Figure 4-5: Boiling convection coefficient variance with injection rate - Sandstone Experiment

The increasing $T_{e}$ with increasing injection rate drives the decreasing $h$ trend.

\subsection{Discussion}

Based upon visual observations, water injected into the fracture penetrated the highly porous and permeable sandstone matrix in a liquid state. Once the water reached a depth within the rock at which the saturation temperature existed, boiling began. It is likely that additional water flowed radially outward slightly above the boiling depth, which presumably became shallower with distance from the central injection point on the disk. The epoxy and silicone boundary applied to the radial edge of the disk halted radial flow, and the water boiled upward to and upon the surface of the disk.

As the injection rate was increased, the boiling depth increased, while the measured $T_{\text {sat }}$ decreased. This was caused by the cooling effect supplied by the higher volumetric flow rate to the fracture, as well as the higher pressure associated with higher injection rate. This particular experiment utilized only one power input from the heater. If additional, higher powers were used, the boiling depth likely would have decreased and $T_{\text {sat }}$ increased for the same injection rates. 


\section{Boiling On a Confined Low Porosity Surface}

\subsection{Boiling In a Fracture Bounded By Graywacke}

After examining the differences in confined boiling on nonporous aluminum and highly porous and permeable sandstone, arguably the extreme cases to be considered for this investigation, the target material of geothermal graywacke was utilized.

\subsection{Experimental Preparation}

The experimental apparatus depicted in Figure 3-1 was used without modification for the graywacke experiment. Some differences existed between the preparation of the sandstone disk and the graywacke disk.

\subsubsection{Experimental Material}

The graywacke employed in this experiment required proper sizing and the installation of thermocouple holes. A disk of graywacke was cut using a diamond-tipped rock saw from a Sulphur Bank-15 well core obtained from The Geysers geothermal field in Northern California. The two sides of the disk were rendered parallel using a surface grinder. The final dimensions of the graywacke disk were approximately $8.3 \mathrm{~cm}$ in diameter, and 2.0 $\mathrm{cm}$ thick. Eight holes were drilled from the outer edge of the disk toward the center to accommodate $1.0 \mathrm{~mm}$ diameter T-type thermocouples.

As in the previous experiments, each of the holes were offset $15^{\circ}$ from the next, and extended to within $1.5 \mathrm{~cm}$ of the disk center. Thus, both the heat flux and temperature gradient normal to the surface of the graywacke were measured near the center of the fracture. The hole diameter was only slightly greater than the thermocouples to insure a tight fit and good thermal contact.

Two holes were installed at each of four prescribed depths from the top of the disk. These depths were $3.0,6.5,10.0$, and $13.5 \mathrm{~mm}$ from the top (fracture surface). The orientation of drilled holes were identical to those installed in the sandstone disk, depicted in Figure 4-1.

A ring of fiber board insulation was placed around the graywacke disk to restrain radial heat flow. The top of the insulating ring was slightly lower than the top of the graywacke disk, to allow water to exit the fracture unchecked. The insulating ring surrounding the graywacke disk was coated with a layer of high temperature epoxy to repel water that exited the fracture during the experiment. Additional gaps were closed with RTV high temperature silicone for waterproofing purposes.

The outer edge of the rock was sealed with epoxy and silicone to prohibit radial liquid flow within the rock and to restrain radial heat conduction. In order to obtain sufficiently 
good thermal contact, a heat sink compound was applied at the interface of graywacke and the heater surface. The rock surface closest to the heater was not coated with high temperature epoxy as was the sandstone Spontaneous imbibition was not anticipated due to the much lower porosity and permeability of the graywacke.

\subsection{Experimental Procedure and Conditions}

As indicated in Figure 3-2, deionized, deaerated water was supplied to a small positive displacement pump. The pump was adjusted to supply discrete rates of 15, 30, and 45 $\mathrm{ml} / \mathrm{min}$. This water was heated to approximately $70^{\circ} \mathrm{C}$ by flowing through a copper coil immersed in a heated water bath. The water was then injected through the center of the glass disk and into the fracture. The fracture aperture was fixed at $0.508 \mathrm{~mm}$.

As in the aluminum and sandstone experiments, power was supplied to the heater using a variac, and the voltage and current monitored with digital multimeters. Power was slowly increased until boiling began at an injection rate of $45 \mathrm{ml} / \mathrm{min}$. It could be assumed that this was the minimum power at which the maximum flow rate would allow boiling in the fracture. Maintaining this initial power, developing temperature gradients were allowed to achieve steady state, and temperature and heat flux data were recorded. Data were collected with the outer edge of the apparatus exposed to atmospheric pressure. The thermocouples installed in the disk recorded the temperature gradients that developed as water flashed to steam in the fracture. The boiling regime and behavior were observed through the glass disk, and the vapor fraction estimated. The pump was then adjusted to supply 30 and $15 \mathrm{ml} / \mathrm{min}$ injection rates, during which the same sequence was followed.

Three power inputs $(300,350$, and $400 \mathrm{Watts})$ were supplied by the heater and were maintained at those levels for each of the three prescribed flow rates. Once steady state conditions were achieved, data was collected. The intent of multiple power inputs was to produce several measurements of the excess temperature at different values of heat flux. These data could be compared to the results from the aluminum experiment, and used to assess the dependence of a boiling convection coefficient for a confined porous surface on power and injection rate.

\subsection{Experimental Observations and Results}

The temperature data from each thermocouple that was collected upon steady state was averaged over the time interval of collection. Because two thermocouples existed at each depth within the graywacke (distance from the fracture), these average values were again averaged to obtain the steady state temperature for that position. Figures 5-1 through 5-3 present the temperature gradients that developed within the graywacke for each combination of injection rates and power inputs. 


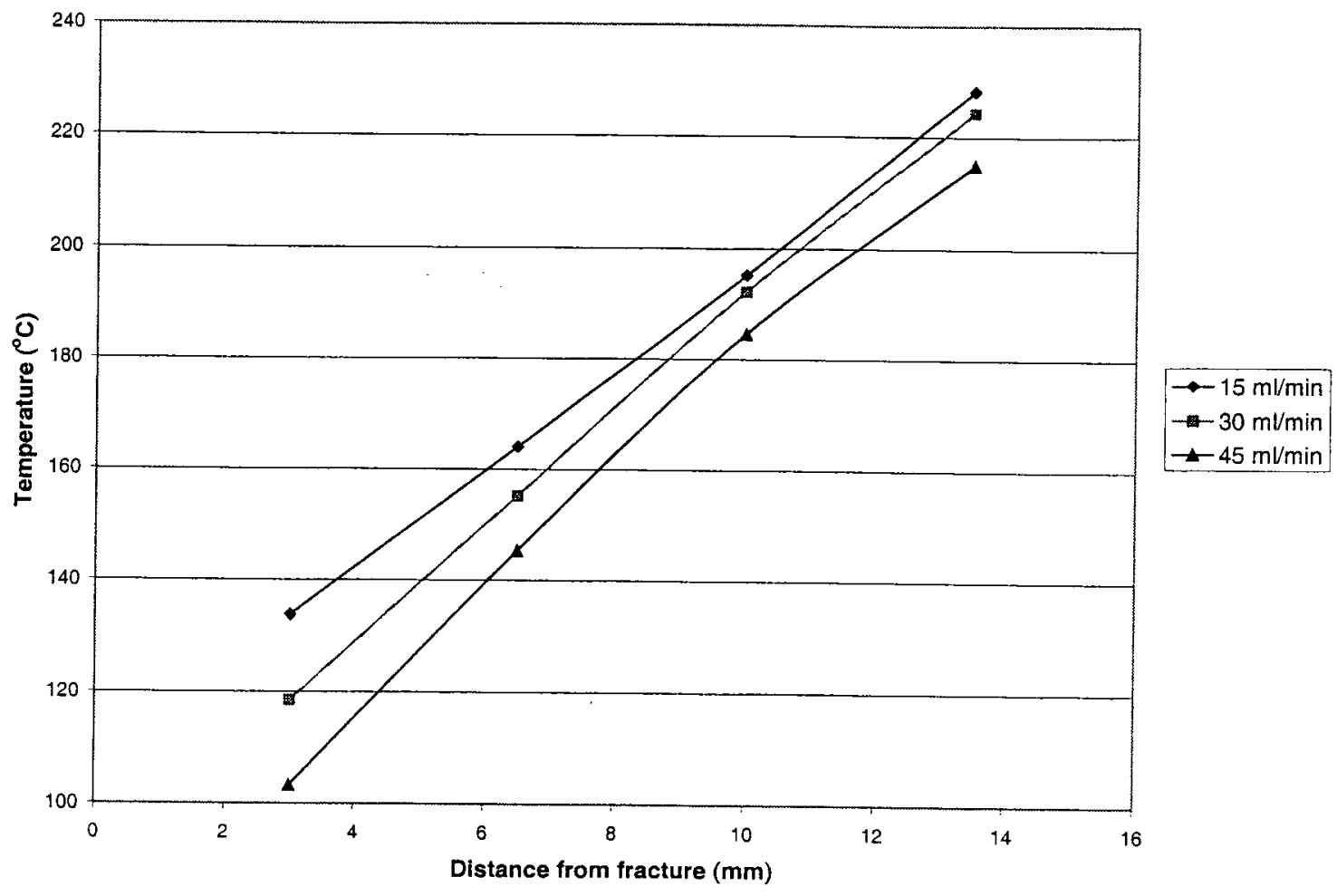

Figure 5-1: Temperature gradients for three flow rates at 300W - Graywacke Experiment 


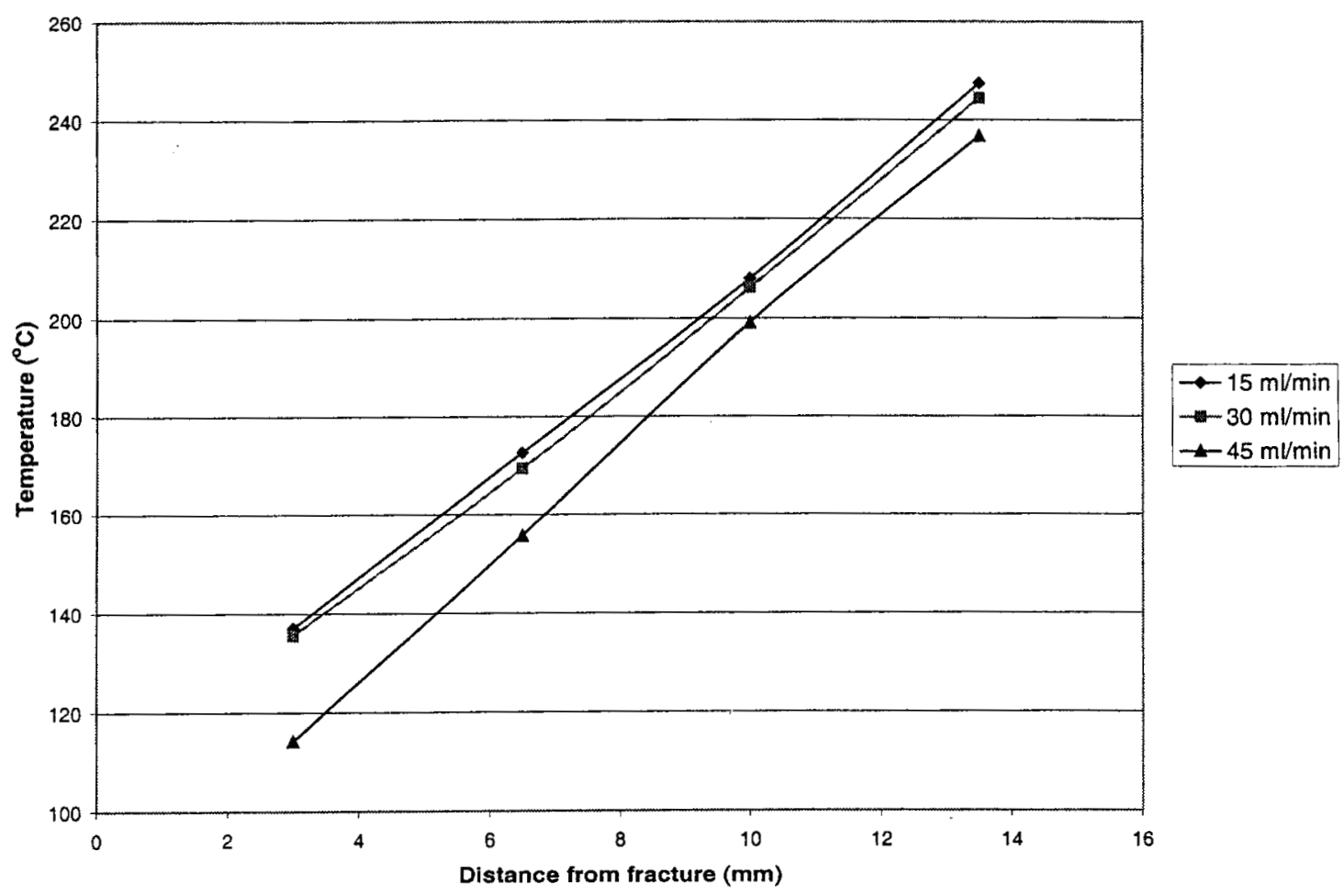

Figure 5-2: Temperature gradients for three flow rates at 350W - Graywacke Experiment 


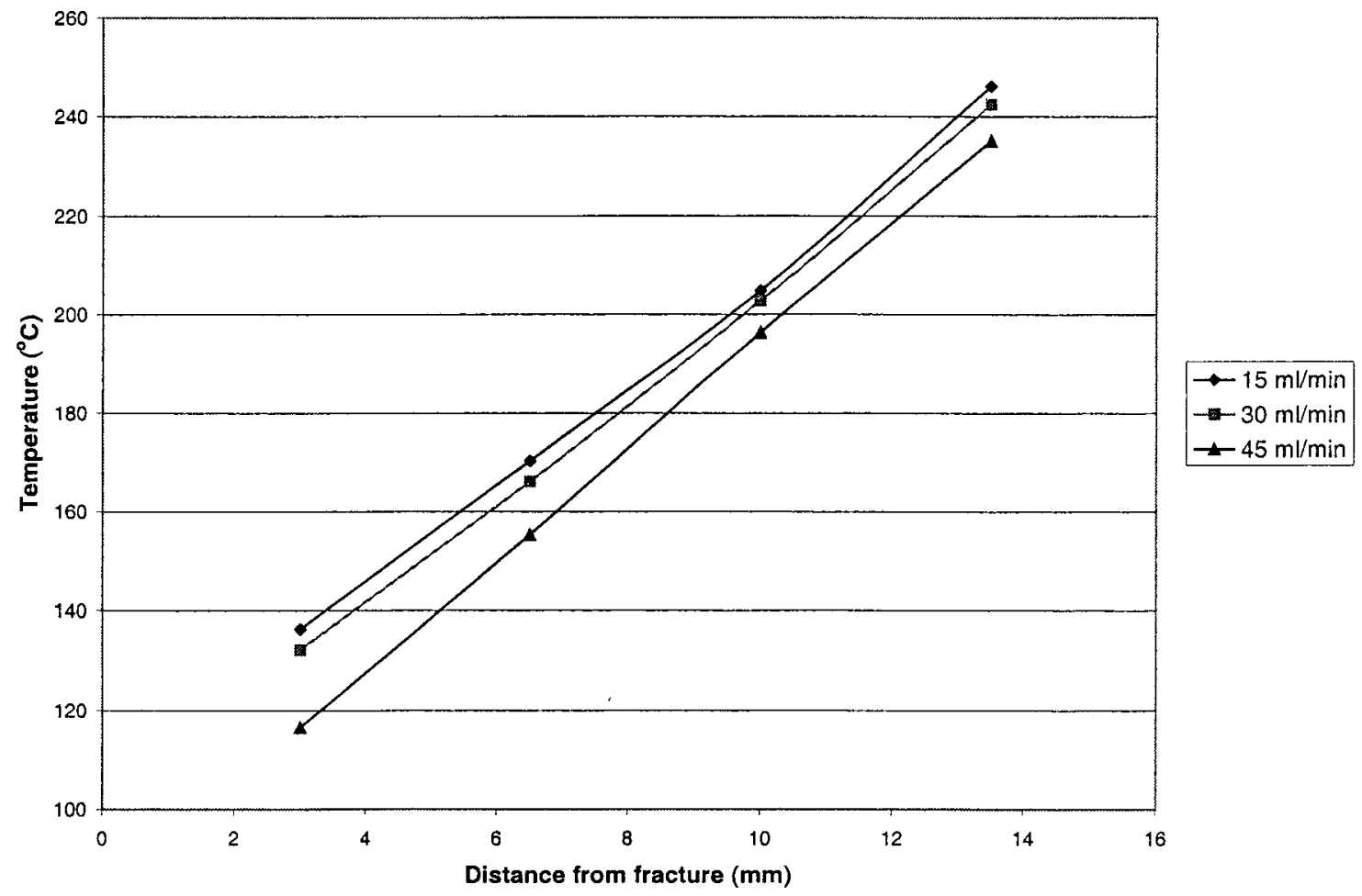

Figure 5-3: Temperature gradients for three flow rates at 400W - Graywacke Experiment The heat flux sensors again failed to provide reliable data. Therefore, as was done previously, values of $q^{\prime \prime}$ were calculated using Fourier's Law of heat conduction and an average thermal conductivity of graywacke $(3.02 \mathrm{~W} / \mathrm{mK}$ ) (Walters 1991). The $d T / d x$ used was that between thermocouples $1(3.0 \mathrm{~mm}$ below surface) and $3(10.0 \mathrm{~mm}$ below surface).

The slope of the temperature gradient between thermocouples 1 ( $3.0 \mathrm{~mm}$ below the surface) and 4 (13.5 $\mathrm{mm}$ below the surface) was used to determine the intercept with $100^{\circ} \mathrm{C}$, and therefore the depth at which boiling occurred in the graywacke.

The excess temperature $T_{e}$ was determined using the values $T_{\text {surf }}$ and $T_{\text {sat }} . T_{\text {sat }}$ was measured by the two J-type thermocouples in the fracture during the experiment. $T_{\text {surf }}$ existed at the calculated depth of boiling in the rock matrix, and was assigned a value of $100^{\circ} \mathrm{C}$. The porous surface boiling value of $T_{e}$ at each flow rate was essentially $100^{\circ} \mathrm{C}$ $T_{\text {sat }}$. However, superheated conditions were attained at $300 \mathrm{~W}(15 \mathrm{ml} / \mathrm{min}), 350 \mathrm{~W}$ (15 and $30 \mathrm{ml} / \mathrm{min})$, and $400 \mathrm{~W}(15 \mathrm{ml} / \mathrm{min})$. Boiling during these injection rate and power combinations did not occur in the rock matrix, but in the fracture. Therefore, the data for these combinations do not quantify the same experimental conditions. Additionally, calculation of $T_{e}$ and $h$ in these superheated cases was performed using the conventional unconfined pool boiling relationship. 
Using the values of heat flux and excess temperature for each power and flow rate combination, the boiling convection coefficient $h$ was calculated. Table $5-1$ presents the results of this experiment.

Table 5-1: Results and Observations - Graywacke Experiment

\begin{tabular}{|ccccccccc|}
\hline $\begin{array}{c}\text { Power } \\
(\text { Watts })\end{array}$ & $\begin{array}{c}\text { Flow Rate } \\
(\mathbf{m l} / \mathbf{m i n})\end{array}$ & $\begin{array}{c}\text { Fraction Boiling Depth } \\
(\%)\end{array}$ & $\begin{array}{c}\mathbf{T}_{\text {surf }} \\
(\mathbf{m m})\end{array}$ & $\begin{array}{c}\mathbf{T}_{\text {sat }} \\
\left({ }^{\circ} \mathbf{C}\right)\end{array}$ & $\begin{array}{c}\mathbf{T}_{\mathbf{e}} \\
\left({ }^{\circ} \mathbf{C}\right)\end{array}$ & $\begin{array}{c}\mathbf{q}^{\mathbf{1}} \\
\left({ }^{\circ} \mathbf{C}\right)\end{array}$ & $\begin{array}{c}\mathbf{h} \\
\left(\mathbf{W} / \mathbf{m}^{2}\right)\end{array}$ & $\left(\mathbf{W} / \mathbf{m}^{2} \mathbf{K}\right)$ \\
\hline \multirow{3}{*}{300} & 15 & 80 & -0.68 & $106.11^{2}$ & 98.32 & 7.79 & 26,500 & $3,401^{3}$ \\
& 30 & 60 & 1.09 & 100 & 95.60 & 4.40 & 31,809 & 7,235 \\
& 45 & 40 & 2.45 & 100 & 85.27 & 14.73 & 35,086 & 2,382 \\
& & & & & & & & \\
350 & 15 & 80 & -0.46 & $104.8^{2}$ & 98.93 & 5.87 & 30,629 & $5220^{3}$ \\
& 30 & $50-60$ & -0.31 & $103.17^{2}$ & 95.57 & 7.60 & 30,464 & $4007^{3}$ \\
& 45 & $30-40$ & 1.74 & 100 & 90.38 & 9.62 & 36,626 & 3,808 \\
& & & & & & & & \\
400 & 15 & 80 & -0.34 & $103.51^{2}$ & 98.64 & 4.87 & 29,587 & $6077^{3}$ \\
& 30 & 50 & 0.07 & 100 & 98.22 & 1.78 & 30,483 & 17,137 \\
& 45 & $30-40$ & 1.57 & 100 & 91.49 & 8.51 & 34,473 & 4,050 \\
\hline
\end{tabular}

${ }^{1}$ Negative value indicates superheated condition and boiling in fracture only.

${ }^{2}$ Value calculated from linear trendline of temperature gradient.

${ }^{3}$ Reflects pool boiling relationship.

As summarized in Table 5-1, the vapor fraction within the fracture decreased with increasing injection rate and slightly with increasing power. Boiling flow in general was violent and highly chaotic. It appeared that water injected at the center of the disk penetrated the graywacke matrix before boiling, then after flowing radially through the rock, exited as boiling flow near the radial edge. Therefore, most of the observed boiling was near the edge of the rock and fracture. However, preferred nucleation sites were still. evident on the graywacke surface. Specific regions of the surface were predominantly occupied by the vapor, rather than liquid phase. In general, the boiling regime upon graywacke more closely resembled that of aluminum than sandstone.

In Figures 5-4 through 5-6, heat flux, excess temperature, and boiling convection coefficient data are graphed over each of the three power inputs and three injection rates. 


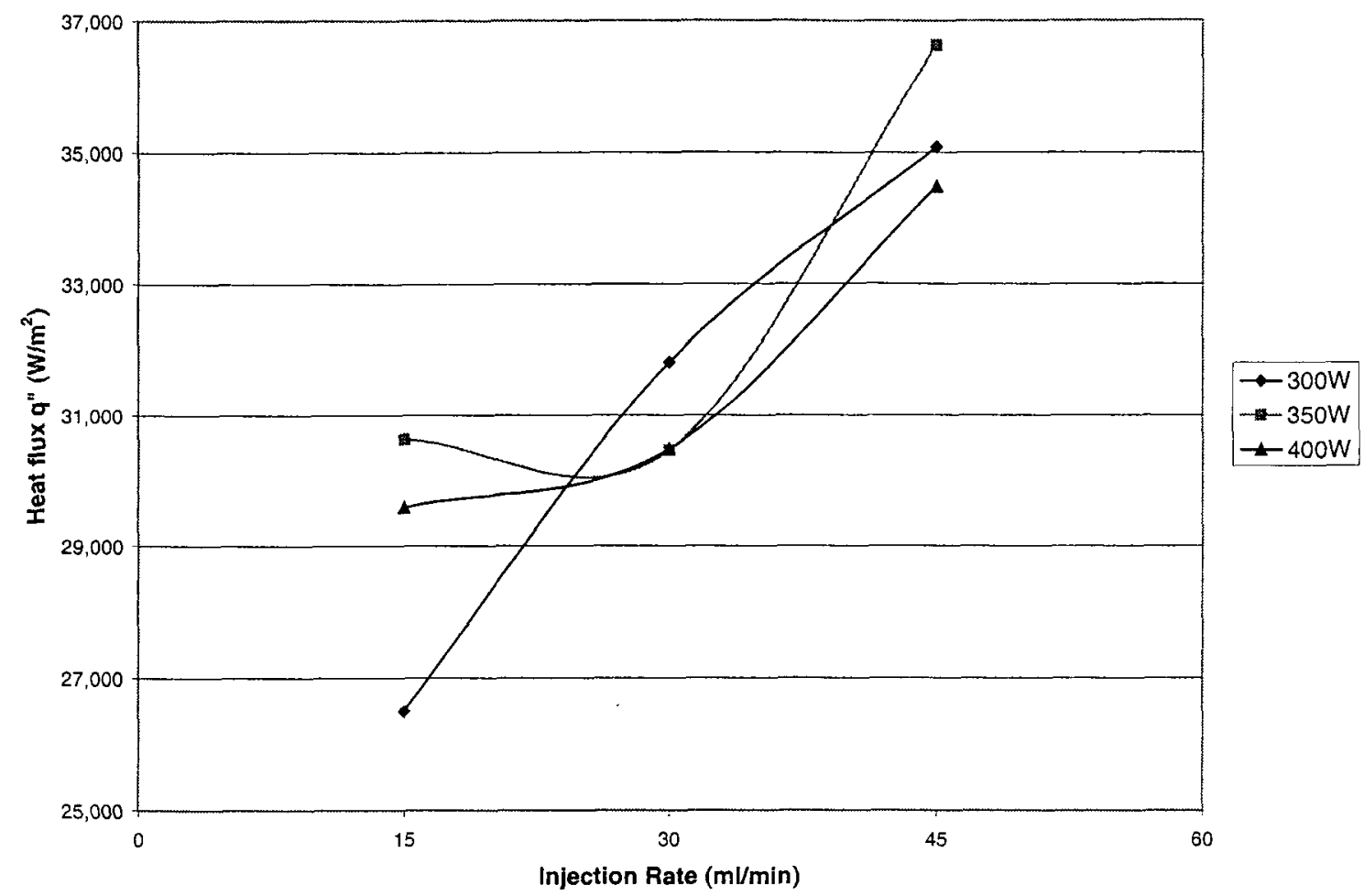

Figure 5-4: Heat flux variance with injection rate - Graywacke Experiment

An approximate linear trend is evident in Figure 5-4. Heat flux is clearly coupled to injection rate for this experimental material. 


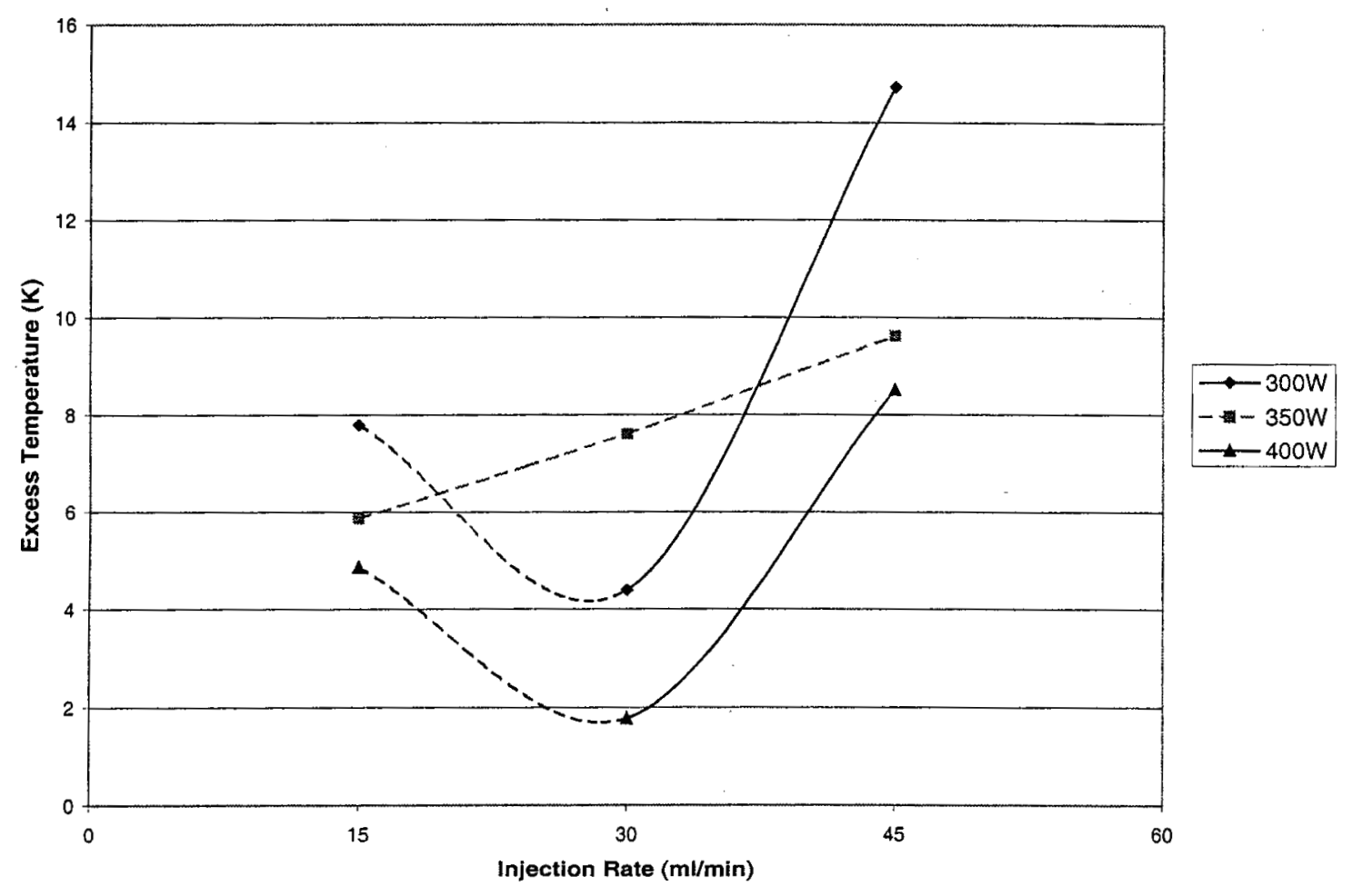

Figure 5-5: Excess temperature variance with injection rate - Graywacke Experiment

Due to the application of the unconfined pool boiling relationship to determine $T_{e}$ in selected experimental cases, the solid trends are the sole applicable results. It does appear that $T_{e}$ is a function of injection rate. 


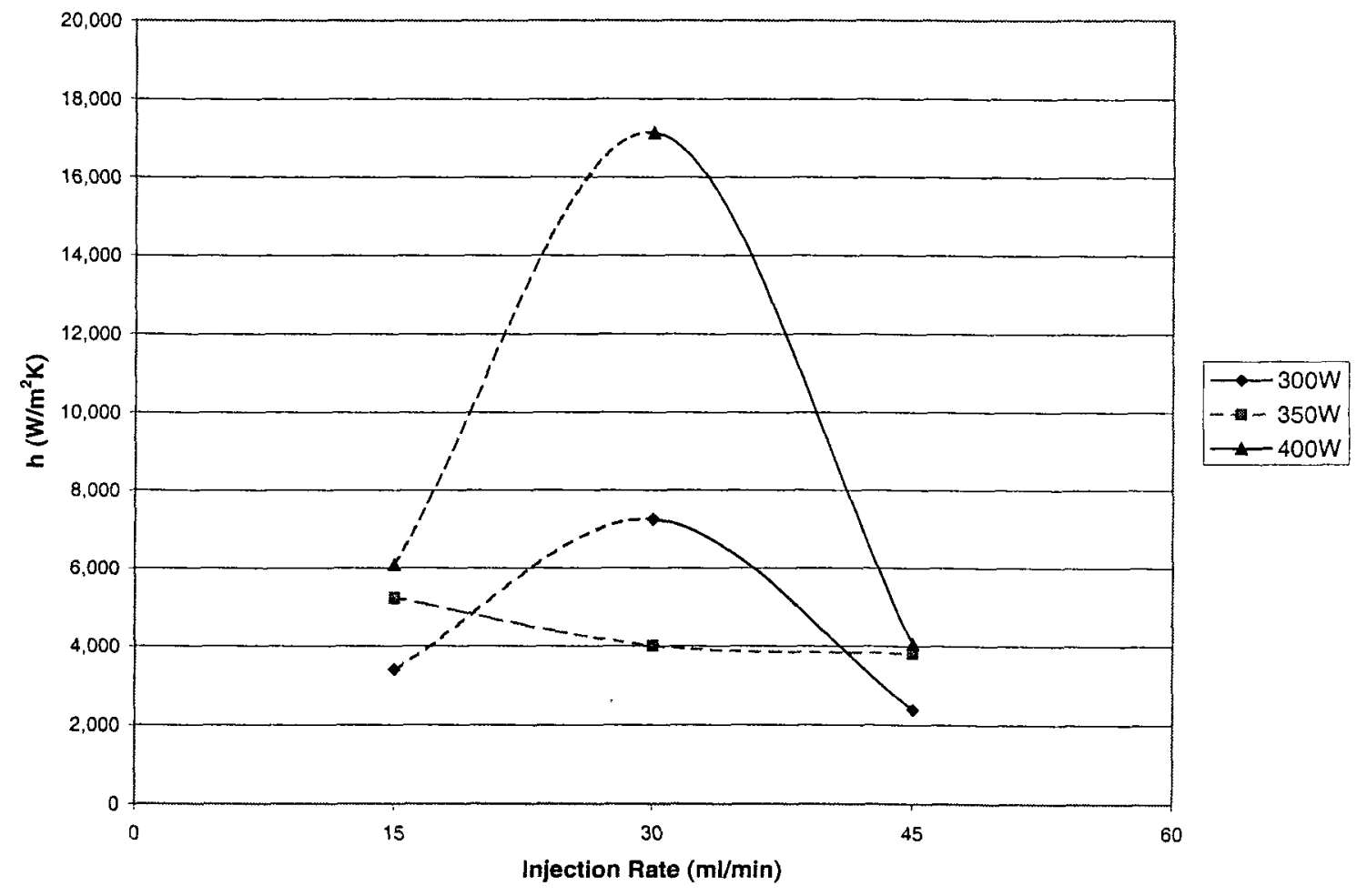

Figure 5-6: Boiling convection coefficient variance with injection rate - Graywacke Experiment

As in Figure 5-5, the application of the unconfined pool boiling relationship to determine $T_{e}$ and therefore $h$ in selected experimental cases, resulted in the solid trends as the sole applicable results. It does appear that $h$ is a function of injection rate.

\subsection{Discussion}

To a lesser extent than the sandstone, and for the selected conditions noted above, water injected into the fracture penetrated the minimally porous and permeable graywacke matrix in a liquid form. Once the water reached a depth within the rock at which saturation temperature existed, boiling began. It is likely that additional water flowed radially outward at the boiling depth, which presumably became shallower with distance from the central injection point on the disk. The epoxy and silicone boundary applied to the radial edge of the disk halted radial flow, and the water boiled upward to and upon the surface of the disk.

As noted in the sandstone experiment, as the injection rate was increased, the boiling depth increased, while the measured $T_{\text {sat }}$ decreased. This was caused by the cooling effect supplied by a higher volumetric flow rate to the fracture, as well as the higher pressure associated with higher injection rate. Additionally, with increasing power supplied to the fracture, the boiling depth in the graywacke matrix became shallower, and the measured $T_{\text {sat }}$ increased. 
For the superheated conditions observed, the calculated $T_{\text {surf }}$ was derived from the linear temperature trend that developed across the graywacke disk. This was utilized in the unconfined pool boiling relationship for $T_{e}$, and subsequently used to calculate $h$. It is therefore difficult to draw any comparison between values of $T_{e}$ and $h$ calculated from superheated conditions to those calculated from conditions in which boiling occurred in the matrix.

As indicated in Table 5-1, the superheated conditions occurred at lower injection rates. This is an expected result due to the increased cooling and penetration effects associated with higher injection rates. Although the data presented in Table 5-1 indicates the interpolated values of $T_{\text {surf }}$ for superheated conditions decrease with increasing power supplied by the heater, this seems unlikely to be true. It is expected that the value of $T_{\text {surf }}$ should increase with increasing power, as observed in the aluminum experiment. Heater malfunction and eventual failure in the later stages of the graywacke experiment may be to blame. 


\section{Conclusions}

\subsection{Data Comparison Over Range of Materials}

Measured data and calculated values for $q^{\prime \prime}, T e$, and $h$ can be compared for each of the three experimental materials employed. Because only one power input was used in the sandstone experiment, data collected for approximately the same power input for the aluminum and graywacke experiments was used for comparison.

\subsubsection{Heat Flux Comparison}

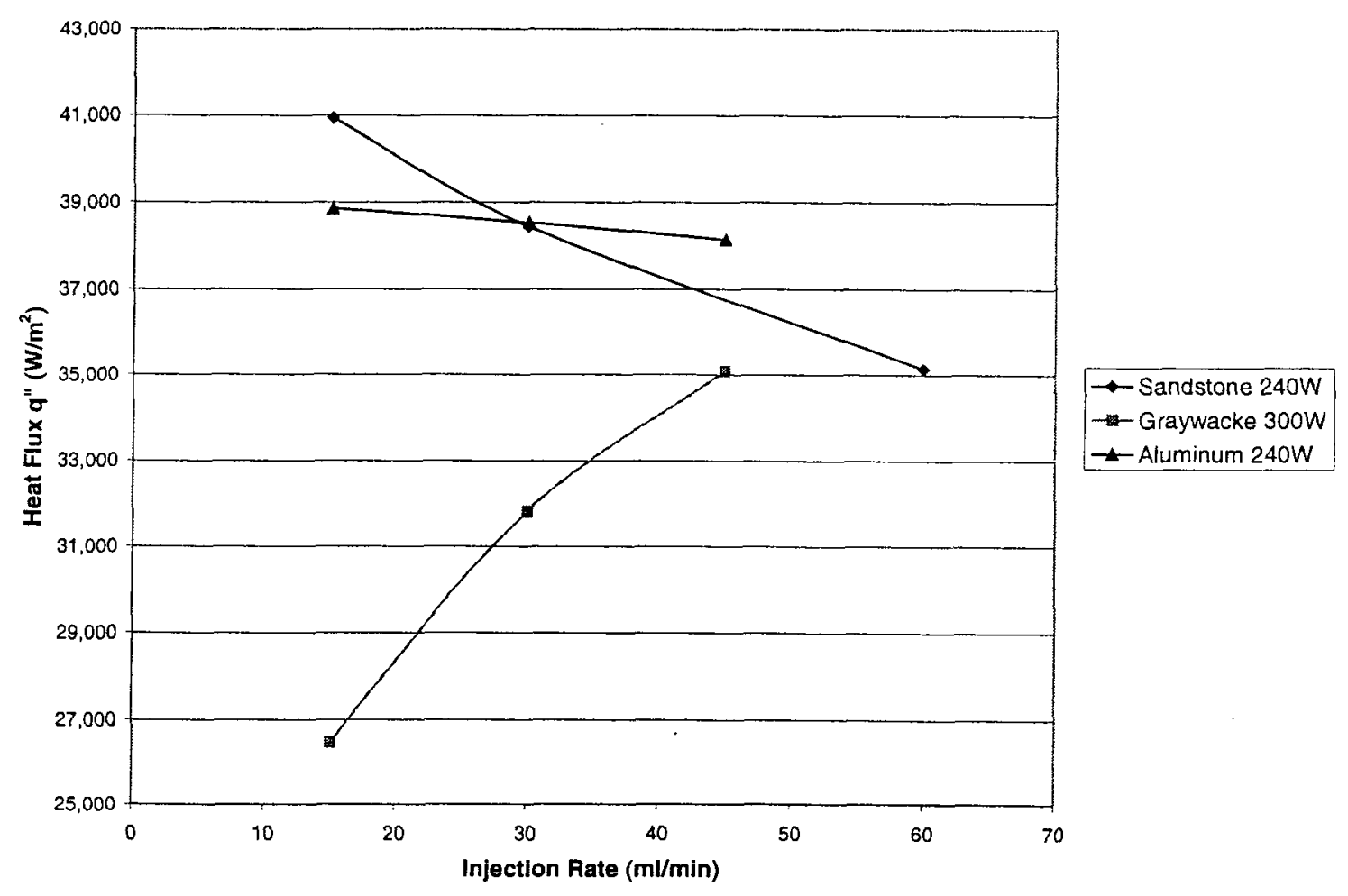

Figure 6-1: Heat flux comparison

Although heat flux is not strongly coupled to injection rate for boiling on a confined nonporous surface, it is coupled for confined boiling on the two porous surfaces.

Due to asperity-induced nucleation sites on the porous surfaces, higher heat fluxes would be expected than for equal powers and injection rates on a nonporous surface. A higher heat flux for sandstone at $15 \mathrm{ml} / \mathrm{min}$ is observed than for aluminum at $15 \mathrm{ml} / \mathrm{min}$. However, for higher injection rates, the sandstone heat flux drops below the relatively 
constant heat flux value. This may indicate the presence of a vapor blanket, in which lower thermal conductivity vapor reduces the heat flux.

Given smaller pores and asperities present in graywacke, heat fluxes slightly higher than those observed in the sandstone would be expected. However, this was not observed. The $15 \mathrm{ml} / \mathrm{min}$ injection rate corresponded with superheated conditions and the absence of boiling in the graywacke matrix. The heat flux increased sharply with higher injection rates, and as boiling began in the matrix.

\subsubsection{Excess Temperature Comparison}

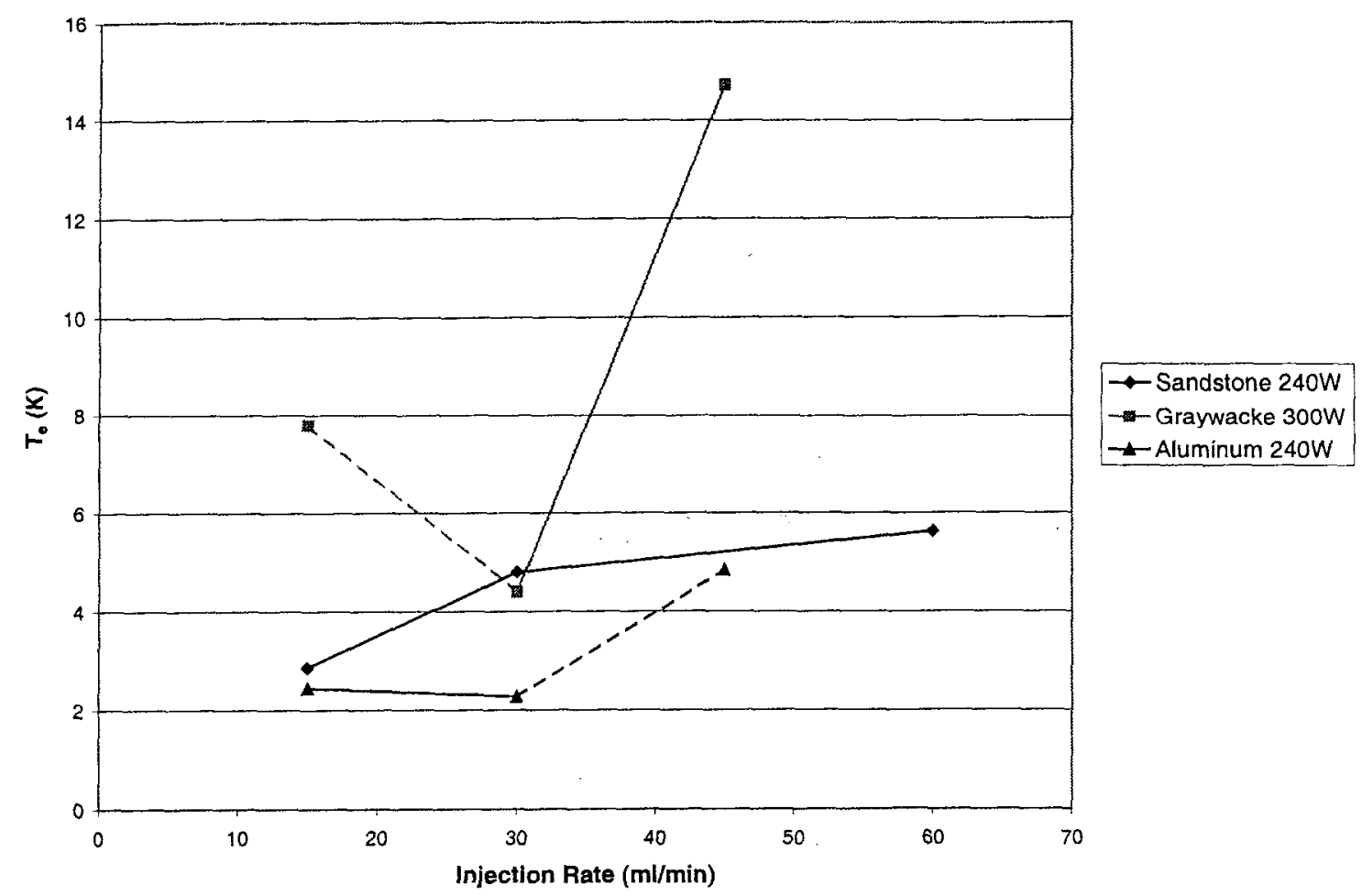

Figure 6-2: Excess temperature comparison

Although $T_{e}$ is not strongly coupled to injection rate for boiling on a confined nonporous surface, it is coupled for confined boiling on the two porous surfaces. $T_{e}$ increases slightly with increasing injection rate for sandstone. A decreasing value of $T_{\text {sat }}$ drives this trend. This subcooled boiling condition is also evident in the increasing $T_{e}$ trend for graywacke. The lower permeability of the graywacke likely led to increased injectate retention in the fracture, and consequently lowered the value of $T_{\text {sat }}$. 


\subsubsection{Boiling Convection Coefficient Comparison}

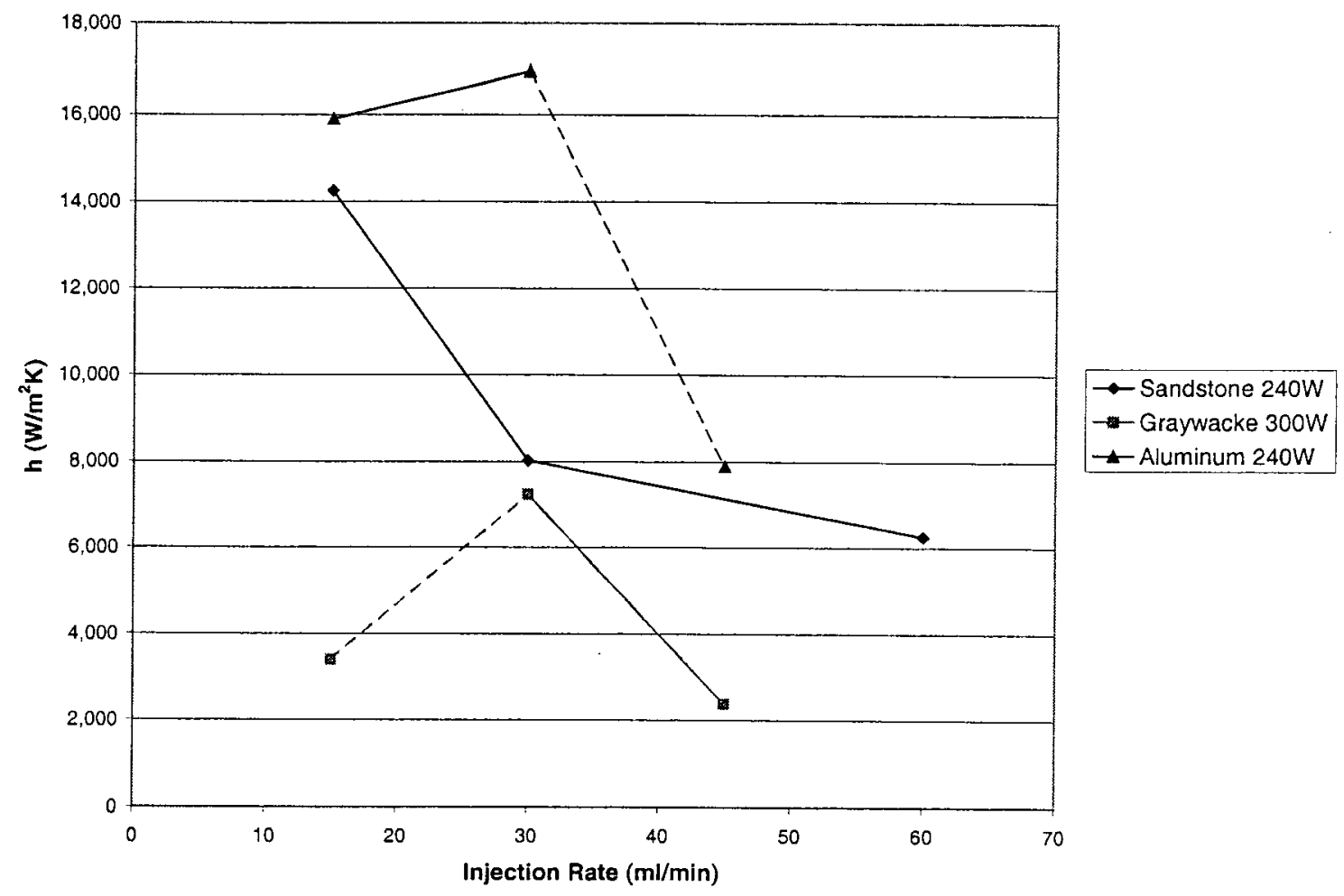

Figure 6-3: Boiling convection coefficient comparison

Although the $h$ is not strongly coupled to injection rate for boiling on a confined nonporous surface, it is coupled for confined boiling on the two porous surfaces. The decreasing trend for sandstone is driven mainly by the decrease in heat flux with increasing injection rate. Although the $q^{\prime \prime}$ and $T_{e}$ trends for graywacke were increasing, the resultant trend is decreasing with increasing injection rate. A maximum for $q^{\prime \prime}$ may not correspond with a maximum $h$ for boiling on graywacke.

\subsection{Depth of Boiling In Porous Materials}

Tables 4-1 and 5-1 indicated the differences in boiling depth for varying injection rates, power inputs, and materials. Figure 6-4 illustrates these differences. Calculated values from superheated conditions are not plotted. 


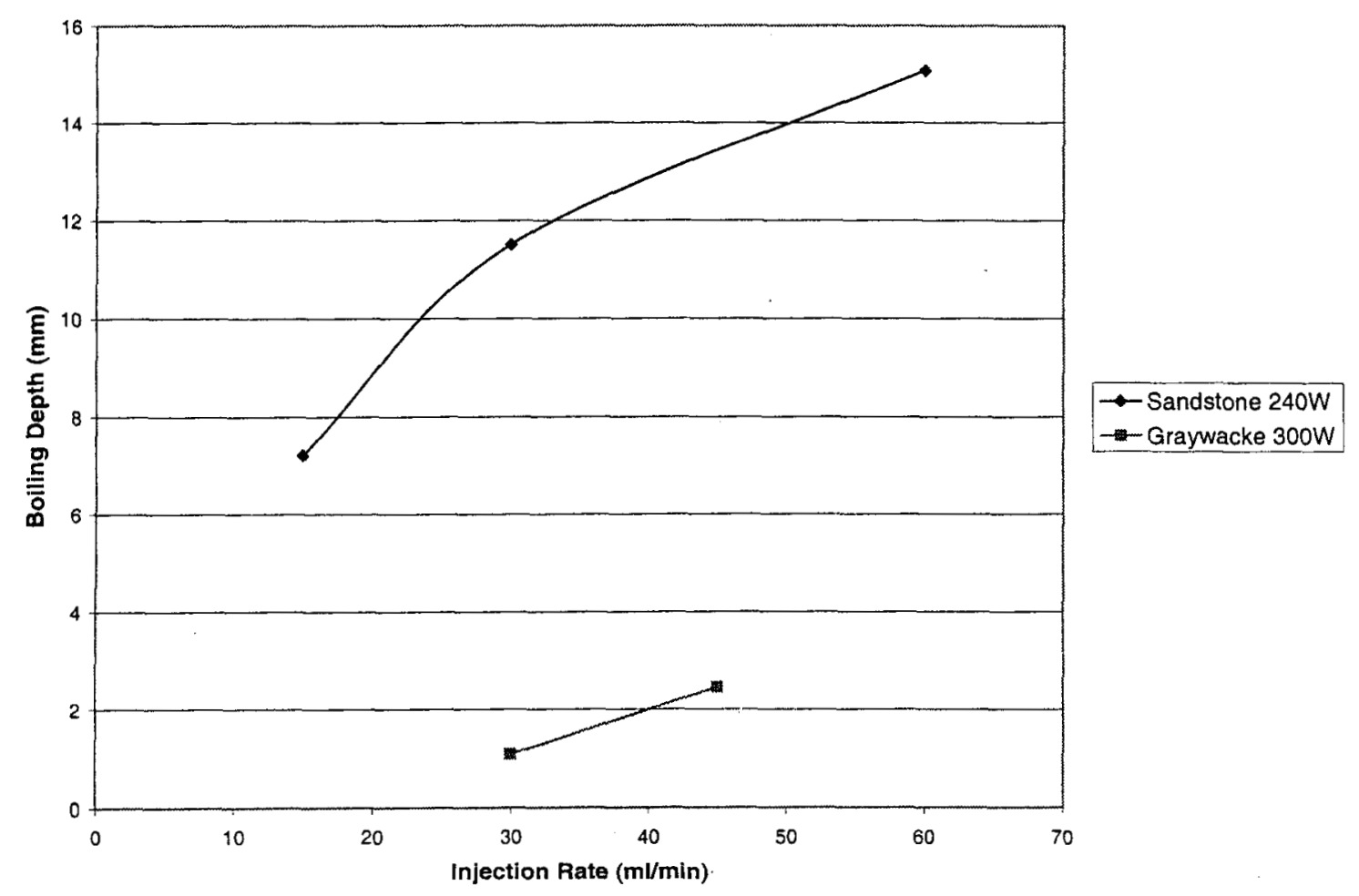

Figure 6-4: Boiling depth variation with injection rate and material

Due to the higher porosity and permeability of the sandstone, injected water is able to penetrate deeper into the matrix before boiling. The larger pores in sandstone may slightly affect the boiling depth, as nucleation will not occur as rapidly (i.e. at a shallower matrix depth) as in the smaller pored graywacke.

\subsection{Application of Results}

Experimental analysis of boiling on a confined, nonporous surface indicated that heat flux was not coupled to injection rate into the simulated fracture. However, injection rate was observed to influence the heat flux with boiling on a confined, porous surface. Visual observations during the experiments indicated that injected fluid penetrated the porous matrix close to the injection point. The fluid penetrated the matrix to a depth at which saturated conditions existed, before radially flowing to the edge of the experimental disk. It is likely that the boiling depth decreased with distance from the point of injection.

Experimental results also indicated that with increasing power supplied to the fracture, the vapor fraction increased, and boiling depth decreased. As indicated in the graywacke experiment, superheated conditions were attained at some low injection rates, resulting in boiling occurring only in the fracture, and not in the matrix. 
Applying these two points to an injection scenario in a fractured geothermal field, it is likely that the magnitude of the injection rate may only affect a finite region close to the point of injection. Boiling may occur in the matrix in this region, but as injected fluid travels along a given fracture, the boiling depth would decrease until superheated conditions applied. At this point, the conventional pool boiling relationship given in Equation 2.1 is appropriate. However, onset of nucleation and therefore the magnitude of the heat flux and boiling convection coefficient are functions of pore size. Although it may be appropriate to model the boiling convection coefficient using the relationship and definitions given in Equation 2.1, another correlation may be required to account for the advanced pore- and asperity-induced nucleation effects. It is worth of note that heat fluxes for graywacke increased with increasing injection rate. This was not observed for either nonporous aluminum or highly porous sandstone, in which a vapor blanket may have formed within the matrix. Further research is appropriate in this area. 



\section{Nomenclature}

$$
\begin{array}{ll}
\text { atm } & =\text { atmosphere } \\
\mathrm{cm} & =\text { centimeters } \\
d T / d x & =\text { temperature gradient } \\
h & =\text { boiling convection coefficient } \\
K & =\text { Kelvin } \\
m^{2} & =\text { square meters } \\
m m & =\text { millimeters } \\
T_{\text {sat }} & =\text { saturation temperature } \\
T_{\text {surf }} & =\text { temperature of a surface upon which boiling occurs } \\
q^{\prime \prime} & =\text { heat flux } \\
W & =\text { Watts }
\end{array}
$$





\section{References}

Berenson, P. J., "Film Boiling Heat Transfer for a Horizontal Surface", J. Heat Transfer, pp. 83, 351, 1961.

Carey, V. P. "Liquid-Vapor Phase Change Phenomena: An Introduction to the Thermophysics of Vaporization and Condensation Processes in Heat Transfer Equipment", Washington, D. C.: Hemisphere Publishing Corp., pp.508-524, 1992.

Calhoun, J. C., and Newman, R. C. (1949), "Experiments on the Capillary Properties of Porous Solids”, Petroleum Transactions, AIME, pp. 189-196, July, 1949.

DuTeaux, R., "Experimental Investigation of Boiling Heat Convection In a Fracture", MS Report, Stanford GeothermalProgram, December, 1998.

DuTeaux, R. J., and Barnitt, R. A., "Experimental Investigation of Boiling Heat Convection With Radial Flow In a Fracture", Proc. $24^{\text {th }}$ Workshop on Geothermal Reservoir Engineering, Stanford University, Stanford, CA, January 1999.

Grant, M. A., Donaldson, I. G., and Bixley, P.F., Geothermal Reservoir Engineering, pp. 255-256, Academic Press Inc., 1982.

Horne, R. N. "Geothermal Reinjection Experience in Japan.", J. Pet. Tech., Vol. 34, pp. 495-503, 1982.

Kovalev, S. A., Solov'yev, S. L., and Ovodkov, O. A. (1987). "Liquid Boiling on Porous Surfaces", Heat Transfer-Soviet Research, Vol. 19, No. 3, May-June 1987.

Pruess, K. "Modeling of Geothermal Reservoirs: Fundamental Processes, Computer Simulation, and Field Applications.", Geothermics, Vol. 19(1) pp. 3-15, 1990.

Solov'ev, S. L., and Kolalev, S. A. (1984), "Heat Transfer in the Evaporation of a Liquid on a Porous Surface", Translated from Teplofizika Vysokikh Temperatur, Vol. 22, No. 3, pp. 528-536.

Styrikovich, M. A., Malyshenko, S. P., Andrianov, A. B., and Talaev, I. V. (1987), "Investigation of Boiling on Porous Surfaces", Heat Transfer-Soviet Research, Vol. 19, No. 1, January-February 1987. 
Udell, K. (1982), "The Thermodynamics of Evaporation and Condensation in Porous Media”, SPE Paper 10779. Presented at SPE California Regional Meeting, San Francisco, CA, March 24-26, 1982.

Walters, M. A., and Combs, J., "Heat Flow in the Geysers-Clear Lake Geothermal Area of Northern California, U.S.A.", Geothermal Resources Council, Monograph on The Geysers Geothermal Field, Special Report No. 17, pp. 43-53, 1991.

Yamagata, K., F. Kirano, K. Nishiwaka, and H. Matsuoka, "Nucleate Boiling of Water on the Horizontal Heating Surface", Mem. Fac. Eng. Kyushu, pp. 15, 98, 1955. 